\title{
The Complex Dielectric Constant of Pure and Sea Water From Microwave Satellite Observations
}

\author{
Thomas Meissner and Frank J. Wentz
}

\begin{abstract}
We provide a new fit for the microwave complex dielectric constant of water in the salinity range between 0-40 ppt using two Debye relaxation wavelengths. For pure water, the fit is based on laboratory measurements in the temperature range between $-20{ }^{\circ} \mathrm{C}$ and $+40{ }^{\circ} \mathrm{C}$ including supercooled water and for frequencies up to $500 \mathrm{GHz}$. For sea water, our fit is valid for temperatures between $-2{ }^{\circ} \mathrm{C}$ and $+29^{\circ} \mathrm{C}$ and for frequencies up to at least $90 \mathrm{GHz}$. At low frequencies, our new model is a modified version of the Klein-Swift model. We compare the results of the new fit with various other models and provide a validation using an extensive analysis of brightness temperatures from the Special Sensor Microwave Imager.
\end{abstract}

Index Terms-Dielectric constant of pure and sea water, microwave radiometers, ocean surface emissivity, permittivity, Special Sensor Microwave/Imager (SSM/I).

\section{INTRODUCTION}

A PRECISE knowledge of the complex dielectric constant (permittivity) $\varepsilon$ of water is essential for studying the radiative transfer of microwave radiation that is emitted by the ocean surface, transmitted through the earth's atmosphere and received by passive microwave sensors. The dielectric constant, which is a function of frequency $\nu$, water temperature $T$, and salinity $S$, enters in two ways into the radiative transfer equations.

The specular ocean surface emissivity $E_{0}$ for polarization $\mathrm{p}$ $[=\operatorname{vertical}(\mathrm{v})$ or horizontal $(\mathrm{h})]$ at earth incidence angle (EIA) $\theta$ is determined by the Fresnel equations

$$
\begin{aligned}
E_{0 p} & =1-\left|r_{p}\right|^{2} \\
r_{v} & =\frac{\varepsilon \cos (\theta)-\sqrt{\varepsilon-\sin ^{2}(\theta)}}{\varepsilon \cos (\theta)+\sqrt{\varepsilon-\sin ^{2}(\theta)}} \\
r_{h} & =\frac{\cos (\theta)-\sqrt{\varepsilon-\sin ^{2}(\theta)}}{\cos (\theta)+\sqrt{\varepsilon-\sin ^{2}(\theta)}}
\end{aligned}
$$

Using Rayleigh approximation, the absorption coefficient $\alpha_{\mathrm{L}}$ (nepers per centimeter) of radiation with wavelength $\lambda$ (centimeters) by a liquid cloud of density $\rho_{\mathrm{L}}$ (grams per cubic centimter) is given by

$$
\alpha_{\mathrm{L}}=\frac{6 \pi \rho_{\mathrm{L}}}{\lambda \rho_{0}} \operatorname{Im}\left(\frac{1-\varepsilon}{2+\varepsilon}\right)
$$

where $\rho_{0} \approx 1 \mathrm{~g} / \mathrm{cm}^{3}$ is the density of water.

\footnotetext{
Manuscript received February 4, 2004; revised May 19, 204. This work was supported by Boeing/AER Investigation for CMIS under Integrated Program Office Contract F04701-02-C-0502.

The authors are with Remote Sensing Systems, Santa Rosa, CA 95401 USA (e-mail: meissner@ remss.com; frank.wentz@ remss.com).

Digital Object Identifier 10.1109/TGRS.2004.831888
}

In the first case, the $\varepsilon$ refers to sea water with a surface temperature $T=T_{\mathrm{S}}$. In the second case, the water is pure, and $T=T_{\mathrm{L}}$ is the temperature of the cloud.

Physical retrieval algorithms for environmental data records (EDRs), such as the sea surface temperature (SST), sea surface wind speed, columnar water vapor and columnar liquid cloud water are derived from a radiative transfer model (RTM), which computes the brightness temperatures that are measured by the satellite as a function of these EDRs. The RTM is based on a model for the sea surface emissivity and the theory of microwave absorption in the earth's atmosphere. The performance of the EDR algorithms depends on the accuracy of sea surface emissivity and, therefore, on the value of the dielectric constant $\varepsilon$. Moreover, the microwave absorption due to liquid cloud water depends directly on the dielectric constant of pure water through (2). As we shall see, this dependence is relatively weak for low-medium frequencies and not too cold temperatures, in the sense that most dielectric models in the literature will predict very close results for the cloud water absorption, even if they differ substantially in their predictions of surface emissivities. The differences between the model cloud absorption predictions increase at higher frequencies (above $100 \mathrm{GHz}$ ) and for supercooled clouds.

So far, microwave radiative transfer calculations have mainly used the dielectric model of Klein and Swift [1]. It fits the dielectric constant with a single Debye relaxation law [2]

$$
\varepsilon(T, S)=\varepsilon_{\infty}+\frac{\varepsilon_{\mathrm{S}}(T, S)-\varepsilon_{\infty}}{1+\left(i \frac{\nu}{\nu_{R}(T, S)}\right)^{1-\eta}}-i \frac{\sigma(T, S)}{\left(2 \pi \varepsilon_{0}\right) \nu} .
$$

Here, $i=\sqrt{-1}, \nu$ is the radiation frequency (in gigahertz), $\varepsilon_{\mathrm{S}}(T, S)$ the static (zero frequency) dielectric constant, $\varepsilon_{\infty}$ is the dielectric constant at infinite frequencies, which is constant in the Klein-Swift model, $\nu_{R}(T, S)$ the Debye relaxation frequency (in gigahertz), $\eta$ the Cole-Cole spread factor [3], which is set to zero in the Klein-Swift model, $\sigma(T, S)$ is the conductivity of water (in siemens per meter) and $\varepsilon_{0}$ is the vacuum electric permittivity, which is determined by $\left(1 / 2 \pi \varepsilon_{0}\right)=17.97510 \mathrm{GHz} \mathrm{m} / \mathrm{S}$. The model parameters $\varepsilon_{\infty}, \varepsilon_{\mathrm{S}}(T, S)$, and $\nu_{R}(T, S)$ were fitted using laboratory measurements of the dielectric constants by Lane and Saxton [4] and the measurements by Ho et al. [5], [6] at 1.43 and $2.653 \mathrm{GHz}$. The Klein-Swift model is sufficiently accurate at very low frequencies but, as it has been shown by various authors [7], [8], it is getting increasingly inaccurate as the frequency increases. Wentz [9]-[11] observed that using the Klein-Swift model above $10 \mathrm{GHz}$ leads to various inconsistencies in retrieving Special Sensor Microwave/Imager (SSM/I) EDRs, especially to an abundance of negative cloud water 
retrievals over cold sea surfaces. An updated analysis for the dielectric constant of pure and sea water for frequencies up to $37 \mathrm{GHz}$ was provided in [11]. It is very similar to the Klein-Swift model, with two exceptions. First, the measurements of Lane and Saxton of the salinity dependence of $\nu_{R}$ were excluded from the data, as they are inconsistent with other measurements. Second, Wentz [11] uses a single Debye relaxation law with a finite spread factor $\eta=0.012$ and a value of $\varepsilon_{\infty}=4.44$, whereas the Klein-Swift model uses $\eta=0$ and $\varepsilon_{\infty}=4.9$.

Liebe et al. [12] state that a second Debye relaxation frequency is needed to fit the experimental data for pure water above $100 \mathrm{GHz}$, and they provide a double Debye fit in the frequency range up to $1 \mathrm{THz}$ based on more recent measurements at high frequencies. It is important to emphasize that it is not clear at this point what the underlying physical process for such a second Debye relaxation is. It should be simply regarded as a necessary parameter, which is needed to provide an accurate fit for the dielectric constant over a wider frequency range than the single Debye model does, while maintaining the necessary analyticity properties in the complex plane that are required by the dispersion relations. A similar approach had been undertaken by Cole and Cole [3], who introduced the "spread factor" $\eta$, which has no relation to a real physical spread of the Debye relaxation frequency. Stogryn [13] provides a double Debye fit for both fresh and sea water in the salinity range between 0-38 ppt. They used their own laboratory measurement in the frequency range between $7-14 \mathrm{GHz}$, which they supplemented with existing measurements. Wang [8] found their model in good agreement with fresh water measurements from the Millimeter-wave Imaging Radiometer (MIR) at 89 and $220 \mathrm{GHz}$. Still, due to the lack of input data, the validity of this model for sea water at higher frequencies needs a closer investigation. The first measurements of $\varepsilon$ for sea water at frequencies above $30 \mathrm{GHz}$ were done by Guillou et al. [7], [14], who found already above $80 \mathrm{GHz}$ that it is insufficient to use a single Debye fit. None of these models have used data for supercooled pure water below $-4{ }^{\circ} \mathrm{C}$, so it is not clear if the models can be applied for supercooled clouds, whose temperatures can be as low as $-20{ }^{\circ} \mathrm{C}$ or even lower.

It is the purpose of this investigation to perform the following.

1) To assess the performance of the various dielectric models for sea water by computing the emissivities and brightness temperatures of passive microwave ocean observations over a wide range of surface temperatures and comparing the results with the measurement. For this purpose, we have analyzed several months worth of SSM/I ocean brightness temperatures at 19.35, 37.0, and $85.5 \mathrm{GHz}$.

2) To provide a fit for the dielectric constant of sea water, which is compatible with both the SSM/I brightness temperature analysis and the validated models of Klein-Swift and Wentz at lower frequencies. The goal is to obtain a model, whose frequency range goes at least up to $90 \mathrm{GHz}$ and, if possible, beyond. From what we mentioned earlier, such a model will necessarily need two Debye relaxation wavelengths.

3) To provide a smooth salinity interpolation between pure and sea water, whose salinity is typically around $35 \mathrm{ppt}$.
4) To extent the fit for pure water to supercooled water with temperatures down to at least $-20^{\circ} \mathrm{C}$, so that the model can be applied to compute the absorption of supercooled clouds.

Our paper is organized as follows. In Section II, we present the SSM/I ocean brightness temperature analysis and statistical results of the comparison with the RTM calculations, which are done with various dielectric models. Section III describes the procedure and results for the double Debye fit of the pure water dielectric constant. We also discuss its implication for fresh water emissivities and liquid cloud water absorption and present a comparison with other dielectric models. In Section IV, we describe the procedure and results for the double Debye fit of the sea water dielectric constant, discuss its implication for ocean surface emissivities, and compare with other models. Section V briefly summarizes our main results and conclusions.

\section{SSM/I BRIGHTNESS TEMPERATURE ANALYSIS}

\section{A. Study Dataset}

Our dataset comprises ocean brightness temperatures that were measured by SSM/I F15 over the four-month period June-September 2002. The dataset also includes the measured earth incidence angles. The Remote Sensing Systems (RSS) Version 5 algorithm (see http://www.remss.com) provides several ocean and atmospheric EDRs: wind speed $10 \mathrm{~m}$ above the ocean surface $W$, columnar water vapor $V$, and columnar liquid cloud water $L$. All of the EDRs have been carefully validated. The events are averaged into $0.25^{\circ}$ latitude-longitude pixels and filtered for land, ice, and rain. Any pixel is discarded if there is land or ice in it or in any of the eight surrounding pixels or if the SSM/I algorithm detects rain in it or in any of the eight surrounding pixels. For a radiative transfer calculation, we need to know the vertical profiles of pressure, temperature, humidity, and liquid cloud water density, which we obtain from the National Centers for Environmental Prediction (NCEP) six hourly final analysis (FNL) at $1^{\circ}$ resolution (see ftp://prd.ncep.noaa.gov Directory:/pub/data/nccf/com/fnl/ $\mathrm{prod} /$ ). It contains 26 temperature and pressure and 21 humidity and cloud water density levels. We also obtain SST from the NCEP analysis. A trilinear interpolation (latitude-longitudetime) is used to match the NCEP data with the SSM/I events. The values for the sea surface salinity $S$ were obtained from [15], and we have used only pixels within the salinity range $20 \mathrm{ppt} \leq S \leq 40 \mathrm{ppt}$.

For studying the surface emissivity, it is desirable to deal with a planar (specular) surface, which is not roughened by wind. Though there exist numerous theoretical surface emission models for computing the emissivity of a wind-roughened surface [16]-[19], these models are not accurate enough for our purposes [11]. Fortunately, for SSM/I earth incidence angles and frequencies, the dependence of the vertical polarized emitted radiation is very small if the wind speed is not too large [20]-[23]. For winds below $5 \mathrm{~m} / \mathrm{s}$, the ocean surface for v-pol radiation can be regarded as specular. We, therefore, limit our study to v-pol radiation and events for which the SSM/I retrieved wind speed is less than $5 \mathrm{~m} / \mathrm{s}$. 

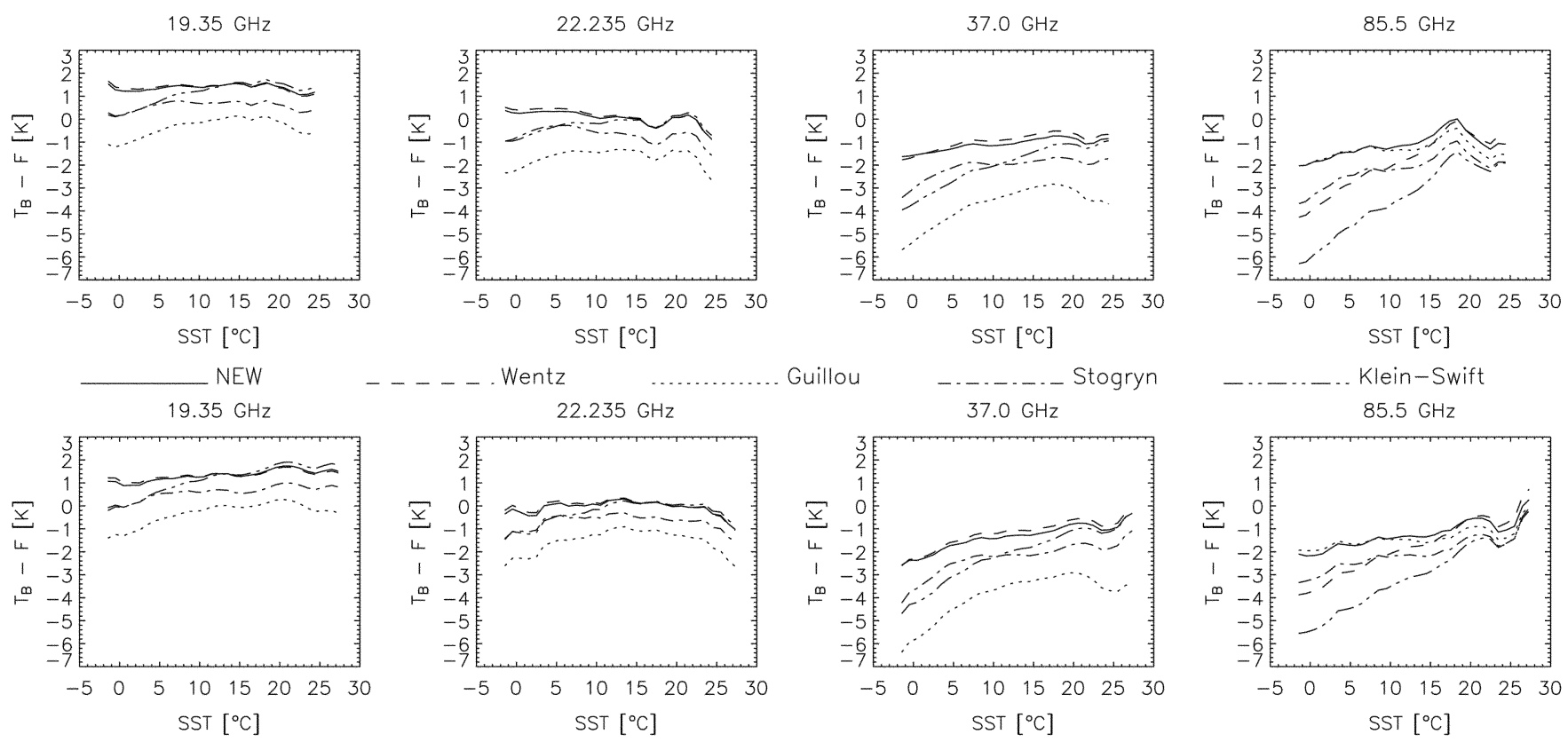

Fig. 1. SSM/I measured minus computed ocean brightness temperatures as a function of surface temperature using various dielectric models at $19.35,37.0$, and $85.5 \mathrm{GHz}$ and vertical polarization. The bin size is $1 \mathrm{~K}$. The upper panel was computed using the water vapor bin $V<10 \mathrm{~mm}$ and the lower panel using the water vapor bin $10 \mathrm{~mm}<V<20 \mathrm{~mm}$.

We have performed our analysis using the water vapor absorption models of Rosenkranz 1998 [24]. Because the total vapor content in the NCEP analysis is known to be accurate to $10 \%$ at best, we are scaling the NCEP water vapor density profiles so that the total vertical integral equals the value $V$ that is retrieved from SSM/I. For the brightness temperature analysis, it is important to reduce possible crosstalk errors between SST and $V$, which arise due to the global correlation between atmospheric moisture content and surface temperature. Areas with warm water likely produce moist atmospheres, whereas dry atmospheres most likely occur over cold water. When analyzing surface emissivity as function of SST, deficiencies in the vapor model or retrieved water vapor could show up in a spurious deficiency of the surface emissivity model. Ideally, the crosstalk between SST and $V$ is minimized, if $V$ varies as little as possible within the analysis dataset. As we shall see, the differences between the various dielectric models are most evident at cold temperatures, which warrants the use of dry atmospheric conditions for our analysis. We have performed the analysis in two different vapor bins: $V<10 \mathrm{~mm}$ and $10 \mathrm{~mm}<V<20 \mathrm{~mm}$. The validity of the Rosenkranz 1998 water vapor absorption model [24] under those dry conditions has been shown by various authors [24], [25]. The oxygen absorption model in our calculations is taken from Rosenkranz's Fortran code O2ABS.FOR, which is based on the works of [26] and [27].

The handling of the NCEP cloud water density profiles requires some special handling as well. The cloud water density recorded by NCEP refers to both liquid and ice clouds. Because at SSM/I frequencies the dielectric constant of ice is very small compared with the dielectric constant of liquid water, the SSM/I only measures absorption by liquid clouds. In order to extract the liquid cloud density from the NCEP cloud water density profiles, we assume that the cloud is water is completely in the liquid phase if the air temperature of the profile level is above
$0{ }^{\circ} \mathrm{C}$ and completely in the ice phase if it is below $-20^{\circ} \mathrm{C}$. For temperatures in between, we linearly interpolate the liquid density as a function of temperature. As it was the case for the total water vapor profiles, we do not use the absolute values of the NCEP liquid cloud water profiles but scale them so that the total vertical integral equals the value $L$ that is retrieved from SSM/I. Furthermore, we limit $L$ to $0.05 \mathrm{~mm}$ in order to avoid errors in the surface emissivity analysis due to uncertainties in the cloud water absorption. Globally, the probability density function for $L$ has a strong peak at $L=0$ and is rapidly decreasing for increasing $L$. This guarantees a sufficient number of events even if $L$ is limited to these small values.

The model brightness temperature $F$ is calculated from the radiative transfer equation [10], [11]

$$
F=T_{\mathrm{BU}}+\tau E_{0} T_{\mathrm{S}}+\tau\left(1-E_{0}\right) T_{\mathrm{BD}}+\tau^{2}\left(1-E_{0}\right) T_{\mathrm{C}} .
$$

$E_{0}$ is the specular sea surface emissivity (1). $T_{\mathrm{C}}=2.7 \mathrm{~K}$ is the cold space temperature. $T_{\mathrm{BU}}$ is the upwelling atmospheric brightness temperature and $T_{\mathrm{BD}}$ the downwelling atmospheric brightness temperature that is reflected at the sea surface. Both quantities are given as weighted integrals of the atmospheric temperature profiles $T(z)$ between the surface $z=0$ and satellite altitude $z=H$

$$
\begin{aligned}
& T_{\mathrm{BU}}=\sec (\theta) \int_{0}^{H} d z \sum_{I} \alpha_{I}(z) T(z) \tau(z, H, \theta) \\
& T_{\mathrm{BD}}=\sec (\theta) \int_{0}^{H} d z \sum_{I} \alpha_{I}(z) T(z) \tau(0, z, \theta)
\end{aligned}
$$

where $\tau\left(h_{1}, h_{2}, \theta\right) \equiv \exp \left[-\sec (\theta) \int_{h_{1}}^{h_{2}} d z \sum_{I} \alpha_{I}(z)\right]$. The total atmospheric transmittance $\tau$ is given by $\tau=\tau(0, H, \theta)$. 
TABLE I

Statistical Results for the v-Pol Model Function $F$ COMPuted With Various Dielectric Models Versus SSM/I Measured Brightness Temperature $T_{\mathrm{B}}$ : Bias of $T_{\mathrm{B}}-F$, STANDARD DEVIation of $T_{\mathrm{B}}-F$, Linear Correlation CoEfFicient $r$, Slope $m$, AND $y$ AXIS INTERCEPTION $t$ (IN KELVIN) OF THE LINEAR REgRESSION $F=m T_{\mathrm{B}}+t$. THE FIT WAS PERFORMED IN TWO DiFFERENT WATER VAPOR BINS: $V<10 \mathrm{~mm}$ AND $10 \mathrm{~mm}<V<20 \mathrm{~mm}$. THE VALUES OF GUILlOU et al. [7] ReFER TO THEIR Single Debye Fit at 19.35, 22.235, AND $37 \mathrm{GHz}$ AND to THEIR NeW MEASUREMENT AT $85.5 \mathrm{GHz}$

\begin{tabular}{|c|c|c|c|c|c|c|c|c|c|c|c|}
\hline & & & & $J<10 \mathrm{n}$ & & & & $10 \mathrm{~m}$ & $<\mathrm{V}<$ & $0 \mathrm{~mm}$ & \\
\hline FREQ & MODEL & BIAS & SDEV & $\mathrm{r}$ & $\mathrm{m}$ & $\mathrm{t}$ & BIAS & SDEV & $\mathrm{r}$ & $\mathrm{m}$ & $\mathrm{t}$ \\
\hline & NEW FIT & 1.386 & 0.660 & 0.915 & 0.840 & 27.296 & 1.414 & 0.801 & 0.966 & 0.897 & 17.743 \\
\hline & Wentz $[10,11]$ & 1.453 & 0.656 & 0.917 & 0.852 & 24.970 & 1.410 & 0.791 & 0.967 & 0.908 & 15.640 \\
\hline 19.35 & Guillou fit [7] & -0.583 & 0.805 & 0.871 & 0.739 & 47.249 & -0.125 & 0.875 & 0.960 & 0.876 & 23.117 \\
\hline & Stogryn [13] & 0.543 & 0.694 & 0.906 & 0.818 & 32.043 & 0.678 & 0.808 & 0.966 & 0.894 & 19.034 \\
\hline & Klein-Swift [1] & 0.780 & 0.813 & 0.869 & 0.728 & 47.996 & 1.343 & 0.926 & 0.957 & 0.837 & 28.854 \\
\hline & NEW & 0.281 & 0.759 & 0.977 & 0.987 & 2.227 & 0.046 & 1.160 & 0.976 & 0.985 & 3.026 \\
\hline & Wentz $[10,11]$ & 0.389 & 0.764 & 0.977 & 0.992 & 1.158 & 0.083 & 1.161 & 0.976 & 0.990 & 1.907 \\
\hline 22.235 & Guillou fit [7] & -1.710 & 0.838 & 0.972 & 0.917 & 17.462 & -1.321 & 1.199 & 0.974 & 0.964 & 8.732 \\
\hline & togryn [13] & -0.522 & 0.779 & 0.976 & 0.964 & 7.365 & -0.572 & 1.161 & 0.976 & 0.978 & 5.046 \\
\hline & Klein-Swift [1] & -0.411 & 0.810 & 0.974 & 0.929 & 13.935 & -0.091 & 1.196 & 0.974 & 0.958 & 8.770 \\
\hline & NEW FIT & -1.266 & 0.519 & 0.917 & 0.928 & 15.972 & -1.224 & 0.800 & 0.892 & 0.890 & 23.894 \\
\hline & Wentz $[10,11]$ & -1.188 & 0.572 & 0.903 & 0.947 & 11.989 & -1.042 & 0.818 & 0.888 & 0.891 & 23.475 \\
\hline 37.0 & Guillou fit [7] & -4.282 & 0.991 & 0.786 & 0.995 & 5.384 & -3.539 & 1.028 & 0.834 & 0.881 & 28.041 \\
\hline & Stogryn [13] & -2.328 & 0.690 & 0.870 & 0.959 & 10.581 & -2.105 & 0.838 & 0.882 & 0.882 & 26.339 \\
\hline & Klein-Swift [1] & -2.731 & 0.922 & 0.808 & 1.000 & 2.738 & -1.859 & 1.129 & 0.789 & 0.802 & 42.585 \\
\hline & NEW FIT & -1.443 & 1.162 & 0.917 & 0.785 & 52.616 & -1.142 & 1.687 & 0.909 & 0.853 & 37.422 \\
\hline & Wentz $[10,11]$ & -2.828 & 1.491 & 0.867 & 0.638 & 88.872 & -1.528 & 1.879 & 0.885 & 0.764 & 59.818 \\
\hline 85.5 & Guillou (meas.) [7] & -1.488 & 1.136 & 0.921 & 0.801 & 48.886 & -1.339 & 1.649 & 0.914 & 0.876 & 31.864 \\
\hline & Stogryn [13] & -2.600 & 1.259 & 0.907 & 0.723 & 68.468 & -1.937 & 1.695 & 0.908 & 0.828 & 44.436 \\
\hline & Klein-Swift [1] & -4.645 & 1.634 & 0.841 & 0.572 & 106.366 & -2.772 & 1.982 & 0.873 & 0.710 & 74.358 \\
\hline
\end{tabular}

The $\alpha_{I}$ denote the atmospheric absorption coefficients for $I=\mathrm{O}$ (oxygen), $\mathrm{V}$ (water vapor), and L (liquid cloud water).

For our study, we have binned the results between $-2{ }^{\circ} \mathrm{C}$ and $+29^{\circ} \mathrm{C}$ with respect to SST into $1-\mathrm{K}$ temperature bins. For $V<10 \mathrm{~mm}$, the SST bin population peaks at $0^{\circ} \mathrm{C}$ with almost 15000 events and declines to about 150 at $25^{\circ} \mathrm{C}$. For $10 \mathrm{~mm}<$ $V<20 \mathrm{~mm}$, the SST bin population increases from about 4000 at $0^{\circ} \mathrm{C}$ to about 19000 at $17^{\circ} \mathrm{C}$ and then decreases to about 100 at $28^{\circ} \mathrm{C}$. Higher SST bins are not sufficiently populated.

\section{B. Statistical Analysis of Measured Versus Computed Brightness Temperatures}

Fig. 1 shows the difference between the SSM/I measured brightness temperatures $T_{\mathrm{B}}$ and the RTM calculation $F$ as a function of the SST for the four SSM/I frequencies 19.35, 22.235 37.0, and 85.5 GHz. The RTM surface emissivities were calculated using the values for the sea water dielectric constant by Klein-Swift [1] (dash-three dots), Wentz [11] (long dashes), Stogryn [13] (dash-dot), and Guillou et al. [7] (dot). In case of the Guillou model, we have taken their single Debye fits at 19.35 and $37.0 \mathrm{GHz}$, whereas at $85.5 \mathrm{GHz}$ we have used the linear temperature interpolation of their new measurements. As they have already pointed out, the single Debye fit is not applicable at $85.5 \mathrm{GHz}$. The figures in the upper panel were computed in the water vapor bin $V<10 \mathrm{~mm}$ and the ones in the lower panel in the water vapor bin $10 \mathrm{~mm}<V<20 \mathrm{~mm}$. The error bars of $T_{\mathrm{B}}-F$ in each SST bin are approximately $0.6 \mathrm{~K} / 0.8 \mathrm{~K}$ (at $19.35 \mathrm{GHz}), 0.7 \mathrm{~K} /$ $1.1 \mathrm{~K}$ (at $22.235 \mathrm{GHz}$ ), $0.4 \mathrm{~K} / 0.7 \mathrm{~K}$ (at $37.0 \mathrm{GHz}$ ) and $1.1 \mathrm{~K} /$ $1.6 \mathrm{~K}$ (at $85.5 \mathrm{GHz}$ ). Here, the first number refers to the water vapor bin $V<10 \mathrm{~mm}$ and the second number to the water vapor bin $10 \mathrm{~mm}<V<20 \mathrm{~mm}$. The numbers show very little dependence on the dielectric model. These errors can result from uncertainties in the atmospheric absorption model, uncertainties in the retrieved geophysical parameters that are used in the model computation, and sensor errors that result in errors of the measured brightness temperatures.

Ideally, the $T_{\mathrm{B}}-F$ curve should be flat, i.e., independent on SST. A small finite constant bias is possible. Instrument calibration errors, e.g., in the spillover, or inaccuracies in the oxygen or water vapor absorption models can lead to an error in the brightness temperatures, which is independent or very little dependent on SST over the dynamical range that we consider in our study. Table I contains several statistical parameters that are relevant for comparing $T_{\mathrm{B}}$ and $F$. The overall bias $\left\langle T_{\mathrm{B}}-F\right\rangle$, the standard deviation $\sigma\left(T_{\mathrm{B}}-F\right)$, the Pearson correlation coefficient $r$, slope $m$, and $y$ axis intercept $t$ of the linear regression $F=m T_{\mathrm{B}}+t$. Fig. 2 shows the histogram for $T_{\mathrm{B}}-F$ using a bin size of $0.2 \mathrm{~K}$ and after subtracting the values of the overall biases. Ideally, the distribution is Gaussian with a narrow width, which only arises because of sensor noise.

The Wentz dielectric model performs best at 19.35 and $37.0 \mathrm{GHz}$. The $22.235-\mathrm{GHz}$ channel is highly sensitive to water vapor, and therefore, the errors are dominated by errors in the water vapor retrievals. Nevertheless, we find a very good performance of the Wentz dielectric model, which is slightly better than the other models. The fact, that the results at $22.235 \mathrm{GHz}$ are consistent with those at $19.35 \mathrm{GHz}$ also indicate that we are correctly modeling the effect of water vapor absorption on the observations. At $85.5 \mathrm{GHz}$, the measurements of Guillou et al. give the best result, which confirms our earlier analysis [23]. At $37 \mathrm{GHz}$, the Guillou model shows a relatively large 

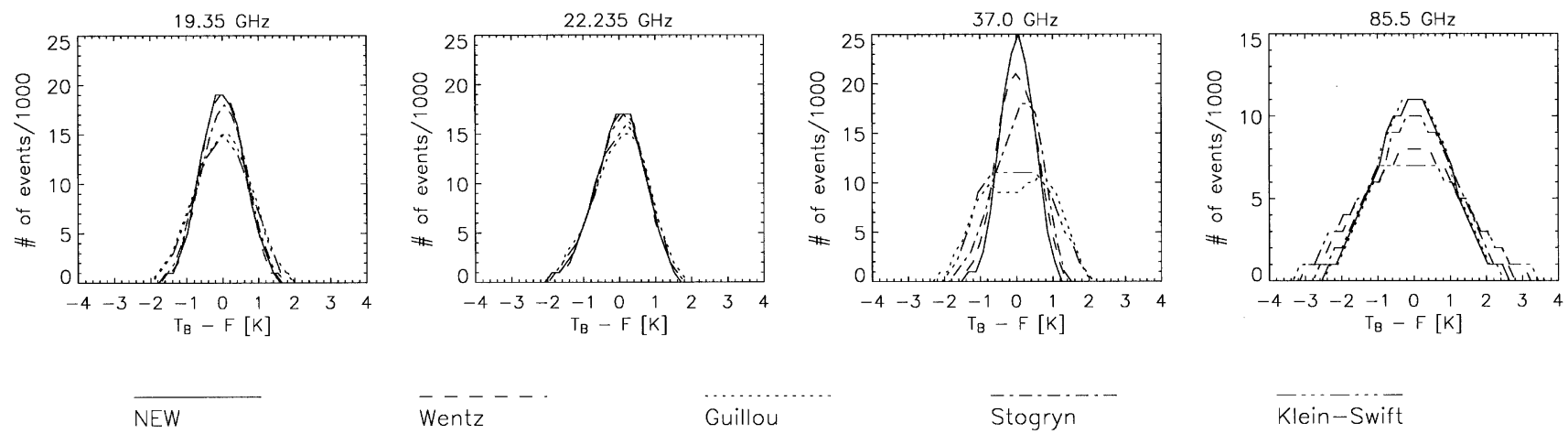

Guillou

$$
\text { Stogryn }
$$

$$
\text { Klein-Swift }
$$
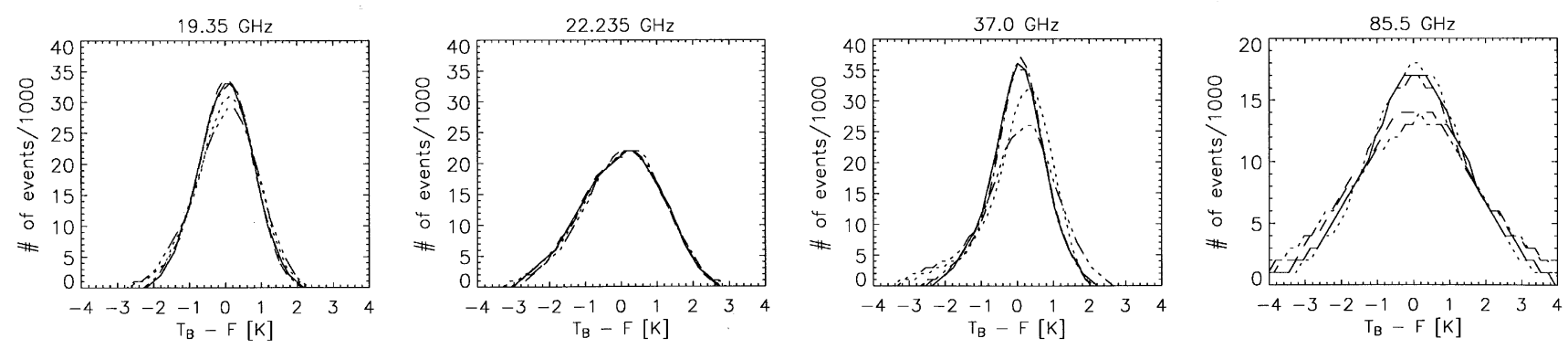

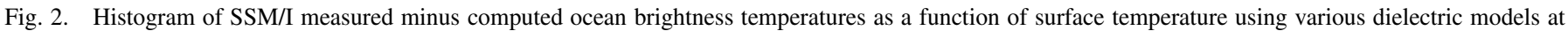

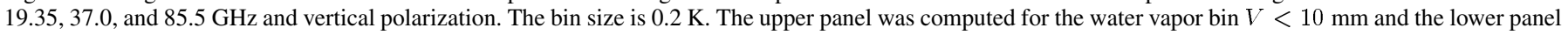
for the water vapor bin $10 \mathrm{~mm}<V<20 \mathrm{~mm}$.

negative bias, especially at cold SSTs, which is equivalent to overestimating the surface emissivity. On the other hand, at $85.5 \mathrm{GHz}$, the Wentz model overestimates the emissivity in cold water. The Stogryn model slightly but still significantly overestimates the emissivity in cold water at both 37 and $85.5 \mathrm{GHz}$. The Klein-Swift model strongly overestimates the cold water emissivity at both 37 and $85.5 \mathrm{GHz}$.

The results of the SSM/I brightness temperature analysis provides us with a clear guideline for fitting the dielectric constant of sea water with 35-ppt salinity using two Debye relaxation frequencies. Below $37 \mathrm{GHz}$, we want to be consistent with the Wentz [11] model and at $85.5 \mathrm{GHz}$ with the results of Guillou et al.[7].

\section{Dielectric Constant of PuRE Water}

\section{A. Two Debye Relaxation Fits for Pure Water}

As stated above, we fit the dielectric constant with a double Debye relaxation law. The general form reads

$$
\begin{aligned}
\varepsilon(T, S)=\frac{\varepsilon_{\mathrm{S}}(T, S)-\varepsilon_{1}(T, S)}{1+i \nu / \nu_{1}(T, S)} & +\frac{\varepsilon_{1}(T, S)-\varepsilon_{\infty}(T, S)}{1+i \nu / \nu_{2}(T, S)} \\
& +\varepsilon_{\infty}(T, S)-i \frac{\sigma(T, S)}{\left(2 \pi \varepsilon_{0}\right) \nu} .
\end{aligned}
$$

We have chosen the convention in which the imaginary part of $\varepsilon$ is negative. Here $\varepsilon_{1}(T, S)$ denotes the intermediate frequency dielectric constant. $\nu_{1}(T, S)$ and $\nu_{2}(T, S)$ are the first and second Debye relaxation frequencies (in gigahertz), respectively. All other symbols have been defined in Section I after (3). The temperature $T$ is in degrees centigrade and the salinity $S$ in parts per trillion. In this section, we will consider pure water where $S=0$ and $\sigma(T, S=0)=0$.
The static dielectric constant for pure water $\varepsilon_{\mathrm{S}}(T, S=0)$ has been measured by several groups (e.g., [28]-[32] and references therein). Wentz [11] used a fit based on the measurements of [30], which have also been reported in [31]. Stogryn [13] used a fit based on the measurements of [29]. Both fits differ by less than $0.03 \%$ over the temperature range between $-21^{\circ} \mathrm{C}$ and $+40{ }^{\circ} \mathrm{C}$. They are also in excellent agreement with the measurements of [28] and the low temperature values of [33]. For reference, we use the fit given in [13]

$$
\varepsilon_{\mathrm{S}}(T, S=0)=\frac{3.70886 \cdot 10^{4}-8.2168 \cdot 10^{1} T}{4.21854 \cdot 10^{2}+T} .
$$

For the temperature dependence of the four fit parameters $\varepsilon_{1}, \varepsilon_{\infty}, \nu_{1}$, and $\nu_{2}$ we make the ansatz

$$
\begin{aligned}
\varepsilon_{1}(T, S=0) & =a_{0}+a_{1} T+a_{2} T^{2} \\
\nu_{1}(T, S=0) & =\frac{45+T}{a_{3}+a_{4} T+a_{5} T^{2}} \\
\varepsilon_{\infty}(T, S=0) & =a_{6}+a_{7} T \\
\nu_{2}(T, S=0) & =\frac{45+T}{a_{8}+a_{9} T+a_{10} T^{2}} .
\end{aligned}
$$

The form for the two relaxation frequencies $\nu_{1}$ and $\nu_{2}$ is inspired by the discussion in [34], which suggests that supercooled water undergoes a phase transition at a critical temperature $T_{\text {crit }}=$ $-45^{\circ} \mathrm{C}$. This would lead to a singularity in the Debye relaxation time $\tau$, which is the inverse of the relaxation frequency

$$
\frac{1}{\nu_{R}} \sim\left(T / T_{\text {crit }}-1\right)^{-\alpha} .
$$

The value of the critical exponent $\alpha$ in [34] lies between 1 and 2.

Table II lists the experimental data that we used for fitting the double Debye relaxation model of pure water. Following [12], 
TABLE II

EXPERIMENTAL DATA FOR THE DIELECTRIC CONSTANT OF PURE WATER, Which We HaVe USED IN THE Fit. For COMPARISON, THE VALUES Obtained With Our New Fit ARE Also Displayed

\begin{tabular}{|c|c|c|c|c|c|c|}
\hline Source & $v[G H z]$ & $T_{S}\left[{ }^{\circ} \mathrm{C}\right]$ & $\begin{array}{l}\operatorname{Re}(\varepsilon) \\
\text { measured }\end{array}$ & $\begin{array}{c}\operatorname{Re}(\varepsilon) \\
\text { fit }\end{array}$ & $\operatorname{Im}(\varepsilon)$ & $\begin{array}{c}\operatorname{Im}(\varepsilon) \\
\text { fit }\end{array}$ \\
\hline Barthel et al. [40] & 1.7 & 25 & 76.92 & 77.83 & 6.64 & 6.42 \\
\hline Barthel et al. [40] & 2.05 & 25 & 76.44 & 77.58 & 7.92 & 7.71 \\
\hline Barthel et al. [40] & 2.5 & 25 & 76.66 & 77.18 & 9.40 & 9.36 \\
\hline Barthel et al. [40] & 4 & 25 & 74.92 & 75.35 & 14.44 & 14.59 \\
\hline Barthel et al. [40] & 4.45 & 25 & 74.49 & 74.66 & 15.55 & 16.07 \\
\hline Barthel et al. [40] & 4.6 & 25 & 73.77 & 74.42 & 17.17 & 16.55 \\
\hline Barthel et al. [40] & 5.35 & 25 & 73.23 & 73.12 & 18.41 & 18.89 \\
\hline Barthel et al. [40] & 5.8 & 25 & 72.58 & 72.27 & 19.65 & 20.22 \\
\hline Barthel et al. [40] & 8.5 & 25 & 65.96 & 66.4 & 26.82 & 27.02 \\
\hline Barthel et al. [40] & 9.2 & 25 & 64.89 & 64.73 & 28.35 & 28.44 \\
\hline Barthel et al. [40] & 10 & 25 & 63.01 & 62.78 & 29.81 & 29.89 \\
\hline Barthel et al. [40] & 11.2 & 25 & 59.98 & 59.83 & 31.58 & 31.74 \\
\hline Barthel et al. [40] & 12 & 25 & 57.95 & 57.86 & 32.72 & 32.77 \\
\hline Barthel et al. [40] & & 25 & 55.47 & 55.42 & 33. & 33.84 \\
\hline Barthel et al. [40] & 14 & 25 & 53.03 & 53.03 & 34.37 & 34.70 \\
\hline Barthel et al. [40] & 15 & 25 & 50.83 & 50.71 & 35.11 & 35.35 \\
\hline hel et al. [40] & & 25 & 47.54 & 47.38 & & 36.01 \\
\hline Barthel et al. [40] & 17.5 & 25 & 45.27 & 45.27 & 35.76 & 36.27 \\
\hline Barthel et al. [40] & 27 & 25 & 29.37 & 30.01 & 33.89 & 34.40 \\
\hline et al. [40] & & & 26.12 & 26.74 & & \\
\hline Barthel et al. [40] & 33 & 25 & 23.56 & 24.01 & 31.22 & 31.68 \\
\hline Barthel et al. [40] & 36 & 25 & 21.65 & 21.73 & 29.96 & 30.29 \\
\hline . [40] & & 25 & 9.53 & 19.83 & 57 & 28.92 \\
\hline Barthel et al. [40] & 60 & 25 & 12.87 & 12.4 & 21.38 & 21.36 \\
\hline Barthel et al. [40] & 66 & 25 & 11.81 & 11.32 & 19.90 & 19.80 \\
\hline al. [40] & 72 & 25 & 11.17 & 10.46 & 18.19 & 18.43 \\
\hline Barthel et al. [40] & 79 & 25 & 10.04 & 9.67 & 17.68 & 17.06 \\
\hline Barthel et al. [40] & 89 & 25 & 8.35 & 8.81 & 15.45 & 15.42 \\
\hline Kaatze et al. [38] & 5 & -4 & 63.81 & 64.56 & 38.38 & 38.41 \\
\hline Kaatze et al. [38] & 10 & -4 & 36.13 & 36.75 & 40.07 & 40.61 \\
\hline Kaatze et al. [38] & 10 & 0 & 42.51 & 42.12 & 40.89 & 40.89 \\
\hline Kaatze et al. [38] & 10 & 10 & 53.40 & 53.46 & 38.22 & 38.17 \\
\hline Kaatze et al. [38] & 10 & 20 & 61.04 & 60.68 & 32.59 & 32.79 \\
\hline Kaatze et al. [38] & 10 & 30 & 64.18 & 64.07 & 27.12 & 27.12 \\
\hline Kaatze et al. [38] & 20 & 0 & 19.55 & 19.34 & 30.79 & 30.69 \\
\hline Kaatze et al. [38] & 20 & 10 & 27.61 & 27.77 & 35.25 & 35.21 \\
\hline Kaatze et al. [38] & 20 & 20 & 36.91 & 36.51 & 36.81 & 36.72 \\
\hline Kaatze et al. [38] & 20 & 30 & 43.92 & 43.83 & 35.70 & 35.47 \\
\hline Kaatze et al. [38] & 30 & 0 & 12.48 & 12.37 & 22.65 & 22.63 \\
\hline Kaatze et al. [38] & 30 & 10 & 17.17 & 17.39 & 27.86 & 27.90 \\
\hline Kaatze et al. [38] & 30 & 20 & 23.76 & 23.52 & 32.00 & 31.84 \\
\hline Kaatze et al. [38] & 30 & 30 & 29.76 & 29.86 & 34.12 & 33.78 \\
\hline Kaatze et al. [38] & 40 & 0 & 9.65 & 9.58 & 17.62 & 17.70 \\
\hline Kaatze et al. [38] & 40 & 10 & 12.54 & 12.78 & 22.35 & 22.46 \\
\hline Kaatze et al. [38] & 40 & 20 & 17.04 & 16.93 & 26.85 & 26.74 \\
\hline & 40 & 30 & 21.38 & 21.65 & 30.17 & 29.86 \\
\hline Kaatze et al. [38] & 50 & 10 & 10.17 & 10.41 & 18.47 & 18.67 \\
\hline
\end{tabular}

we have produced metadata from the single Debye fit of Kaatze and Uhlendorf [35] for frequencies between 5-60 GHz. Other than in [12], we have not used metadata for higher frequencies from this source, because Kaatze and Uhlendorf [35] have re-
TABLE II

(Continued). EXPERIMENTAL DATA FOR THE DIELECTRIC CONSTANT OF PURE WATER, Which We HAVE UsED IN THE Fit. For COMPARISON, THE Values Obtained With Our New Fit ARE Also Displayed

\begin{tabular}{|c|c|c|c|c|c|c|}
\hline Kaatze et al. [38] & 50 & 20 & 13.35 & 13.32 & 22.74 & 22.71 \\
\hline Kaatze et al. [38] & 50 & 30 & 16.40 & 16.78 & 26.31 & 26.08 \\
\hline Kaatze et al. [38] & 60 & 10 & 8.81 & 9.05 & 15.68 & 15.94 \\
\hline Kaatze et al. [38] & 60 & 20 & 11.17 & 11.16 & 19.57 & 19.63 \\
\hline Kaatze et al. [38] & 60 & 30 & 13.29 & 13.74 & 23.06 & 22.92 \\
\hline Bertolini et al. [36] & 9.61 & -21 & 15.40 & 15.56 & 29.00 & 29.61 \\
\hline Bertolini et al. [36] & 9.61 & -20 & 17.00 & 16.97 & 30.80 & 31.01 \\
\hline Bertolini et al. [36] & 9.61 & -19 & 17.60 & 17.42 & 31.50 & 31.43 \\
\hline Bertolini et al. [36] & 9.61 & -18 & 19.20 & 19.04 & 32.50 & 32.84 \\
\hline Bertolini et al. [36] & 9.61 & -18 & 19.50 & 19.28 & 32.40 & 33.03 \\
\hline Bertolini et al. [36] & 9.61 & -16 & 21.70 & 21.37 & 34.70 & 34.61 \\
\hline$\underline{\text { Bertolini et al. [36] }}$ & 9.61 & -11 & 27.70 & 27.62 & 39.10 & 38.16 \\
\hline Bertolini et al. [36] & 9.61 & -8 & 31.80 & 31.55 & 40.80 & 39.63 \\
\hline Bertolini et al. [36] & 9.61 & -6 & 35.60 & 35.38 & 41.60 & 40.58 \\
\hline Bertolini et al. [36] & 9.61 & -3 & 39.80 & 39.71 & 42.20 & 41.10 \\
\hline Bertolini et al. [36] & 9.61 & 0 & 43.10 & 43.61 & 41.80 & 41.05 \\
\hline Bertolini et al. [36] & 9.61 & 1 & 45.70 & 46.03 & 41.00 & 40.77 \\
\hline Bertolini et al. [36] & 9.61 & 3 & 48.40 & 48.1 & 40.70 & 40.38 \\
\hline Bertolini et al. [36] & 9.61 & 6 & 51.70 & 51.79 & 38.70 & 39.25 \\
\hline Bertolini et al. [36] & 9.61 & 10 & 55.20 & 55.19 & 37.90 & 37.66 \\
\hline Bertolini et al. [36] & 9.61 & 14 & 57.90 & 58.27 & 35.90 & 35.62 \\
\hline Bertolini et al. [36] & 9.61 & 17 & 60.30 & 60.54 & 33.10 & 33.59 \\
\hline$\underline{\text { Bertolini et al. [36] }}$ & 9.61 & 32 & 65.80 & 65.17 & 25.00 & 25.22 \\
\hline Hasted et al. [39] & 176 & 10 & 5.71 & 5.79 & 7.10 & 6.36 \\
\hline Hasted et al. [39] & 176 & 20 & 5.73 & 5.98 & 7.79 & 7.81 \\
\hline Hasted et al. [39] & 176 & 30 & 6.28 & 6.21 & 8.99 & 9.19 \\
\hline Hasted et al. [39] & 176 & 40 & 6.24 & 6.57 & 9.98 & 10.35 \\
\hline Hasted et al. [39] & 205 & 10 & 5.41 & 5.57 & 6.24 & 5.64 \\
\hline Hasted et al. [39] & 205 & 20 & 5.58 & 5.69 & 7.11 & 6.86 \\
\hline Hasted et al. [39] & 205 & 30 & 5.85 & 5.84 & 8.16 & 8.01 \\
\hline Hasted et al. [39] & 205 & 40 & 5.78 & 6.13 & 9.00 & 8.97 \\
\hline Hasted et al. [39] & 234 & 10 & 5.35 & 5.39 & 5.57 & 5.10 \\
\hline Hasted et al. [39] & 234 & 20 & 5.55 & 5.46 & 6.37 & 6.14 \\
\hline Hasted et al. [39] & 234 & 30 & 5.60 & 5.58 & 7.34 & 7.10 \\
\hline Hasted et al. [39] & 234 & 40 & 5.68 & 5.83 & 8.16 & 7.92 \\
\hline Hasted et al. [39] & 264 & 10 & 5.29 & 5.23 & 4.95 & 4.66 \\
\hline Hasted et al. [39] & 264 & 20 & 5.35 & 5.28 & 5.61 & 5.54 \\
\hline Hasted et al. [39] & 264 & 30 & 5.36 & 5.38 & 6.43 & 6.35 \\
\hline Hasted et al. [39] & 264 & 40 & 5.51 & 5.61 & 7.19 & 7.05 \\
\hline Hasted et al. [39] & 293 & 10 & 5.21 & 5.1 & 4.44 & 4.31 \\
\hline Hasted et al. [39] & 293 & 20 & 5.16 & 5.14 & 4.94 & 5.07 \\
\hline Hasted et al. [39] & 293 & 30 & 5.21 & 5.23 & 5.54 & 5.77 \\
\hline Hasted et al. [39] & 293 & 40 & 5.34 & 5.46 & 6.32 & 6.38 \\
\hline Hasted et al. [39] & 322 & 10 & 5.15 & 4.98 & 4.14 & 4.01 \\
\hline Hasted et al. [39] & 322 & 20 & 5.10 & 5.02 & 4.50 & 4.67 \\
\hline Hasted et al. [39] & 322 & 30 & 5.16 & 5.12 & 5.05 & 5.28 \\
\hline Hasted et al. [39] & 322 & 40 & 5.30 & 5.35 & 5.76 & 5.82 \\
\hline Hasted et al. [39] & 351 & 10 & 5.05 & 4.88 & 3.78 & 3.76 \\
\hline Hasted et al. [39] & 351 & 20 & 5.04 & 4.92 & 4.20 & 4.34 \\
\hline
\end{tabular}

ported only one measurement above $60 \mathrm{GHz}$, and we anticipate that the single Debye fit is getting inaccurate at higher fre- 
TABLE II

(Continued). EXPERIMENTAL DATA FOR THE DiElectric CONSTANT OF PURE Water, Which We HaVE USED IN THE Fit. For COMPARISON, THE VALUES ObTained With OUR NeW Fit ARE Also DisPlayed

\begin{tabular}{l|c|c|c|c|c|c}
\hline Hasted et al. [39] & 351 & 30 & 5.12 & 5.03 & 4.72 & 4.87 \\
\hline Hasted et al. [39] & 351 & 40 & 5.26 & 5.26 & 5.32 & 5.35 \\
\hline Hasted et al. [39] & 381 & 10 & 5.02 & 4.78 & 3.46 & 3.52 \\
\hline Hasted et al. [39] & 381 & 20 & 4.94 & 4.84 & 3.85 & 4.03 \\
\hline Hasted et al. [39] & 381 & 30 & 5.13 & 4.96 & 4.28 & 4.50 \\
\hline Hasted et al. [39] & 381 & 40 & 5.16 & 5.19 & 4.88 & 4.94 \\
\hline Hasted et al. [39] & 410 & 10 & 4.86 & 4.7 & 3.57 & 3.33 \\
\hline Hasted et al. [39] & 410 & 20 & 5.02 & 4.77 & 3.56 & 3.78 \\
\hline Hasted et al. [39] & 410 & 30 & 5.25 & 4.9 & 3.97 & 4.20 \\
\hline Hasted et al. [39] & 410 & 40 & 5.04 & 5.13 & 4.54 & 4.60
\end{tabular}

TABLE III

PARAMETERS OF THE FIT (8) FOR PURE WATER

\begin{tabular}{c|c}
\hline$i$ & $a_{i}$ \\
\hline 0 & $5.7230 \mathrm{E} 00$ \\
\hline 1 & $2.2379 \mathrm{E}-02$ \\
\hline 2 & $-7.1237 \mathrm{E}-04$ \\
\hline 3 & $5.0478 \mathrm{E} 00$ \\
\hline 4 & $-7.0315 \mathrm{E}-02$ \\
\hline 5 & $6.0059 \mathrm{E}-04$ \\
\hline 6 & $3.6143 \mathrm{E} 00$ \\
\hline 7 & $2.8841 \mathrm{E}-02$ \\
\hline 8 & $1.3652 \mathrm{E}-01$ \\
\hline 9 & $1.4825 \mathrm{E}-03$ \\
\hline 10 & $2.4166 \mathrm{E}-04$ \\
\hline
\end{tabular}

quencies. As [12] and [13] did, we rely on the measurements of Hasted et al. [36] for frequencies between 100-500 GHz, but we did not go beyond $500 \mathrm{GHz}$. Below $100 \mathrm{GHz}$, we have included the measurements by Barthel et al. at $25^{\circ} \mathrm{C}$ [37]. The only measurements for supercooled water were done by Bertolini et al. at $9.61 \mathrm{GHz}$ and comprise the temperature range between $-21^{\circ} \mathrm{C}$ and $+31^{\circ} \mathrm{C}$ [33]. We did include this dataset in our fit, which was not done neither in [12] nor [13].

The 11 fit parameters $a_{i}, i=0, \ldots, 10$ are determined by minimizing the square deviation between data and fit function (6)-(8) for real and imaginary parts of the dielectric constant

$$
Q^{2}=\sum_{i} w_{i}^{1}\left[\operatorname{Re}\left(\varepsilon_{i}^{\text {meas }}-\varepsilon_{i}^{\mathrm{fit}}\right)\right]^{2}+w_{i}^{2}\left[\operatorname{Im}\left(\varepsilon_{i}^{\text {meas }}-\varepsilon_{i}^{\mathrm{fit}}\right)\right]^{2} .
$$

The index $i$ runs over all data that are listed in Table II. We have used equal weights $w_{i}^{1}=w_{i}^{2}=1$.

After numerical minimization of (10), we obtain the values for $a_{i}, i=0, \ldots, 10$ in Table III. Table IV lists the $\sqrt{Q^{2}}$ values between the experimental datasets from Table II and various models including our new fit. Fig. 3 shows the real and imaginary part of $\varepsilon$ at a temperature of $0{ }^{\circ} \mathrm{C}$ as function of frequency for our new fit and the models mentioned above. Figs. 4-7 display the temperature dependence of the parameters $\nu_{1}, \nu_{2}, \varepsilon_{1}$, and $\varepsilon_{\infty}$. The form (9) dictates the behavior of our fit for $\nu_{1}$ and $\nu_{2}$ at very low temperatures. Liebe et al. [12] have assumed in their fit that $\nu_{2}$ and $\nu_{1}$ are related by a simple scale factor. Our results do not support this scaling hypothesis. Stogryn [13] also observed that the scaling hypothesis does not hold in their fit. We want to stress that the lack of measurements for supercooled water at high frequencies does not allow a safe determination of the second Debye relaxation frequency $\nu_{2}$ and the parameter $\varepsilon_{\infty}$ at those temperatures. Our values as well as the value for the dielectric constant at larger frequencies can, therefore, be merely regarded as an extrapolation from temperatures above $0^{\circ} \mathrm{C}$. This will necessarily limit the predictive power of our and any other model in these cases.

\section{B. Implications for the Specular Emissivity of Fresh Water}

In order to quantitatively assess the differences in the prediction of fresh water surface emissivities between the various models, we have plotted the surface-emitted brightness temperatures $E_{0}\left(T=T_{\mathrm{S}}, S=0\right) \cdot T_{\mathrm{S}}$ as a function of $T_{\mathrm{S}}$ at $37,85.5$, and $170 \mathrm{GHz}$ and v-pol and h-pol at $53^{\circ}$ EIA as well as for nadir observations in Fig. 8. The plot shows the differences between Wentz [11] (dashed), Stogryn [13] (dashed-dot), Klein-Swift [1] (dashed-dot-dot), Liebe [12] (dotted), and the result of our new fit. At $37 \mathrm{GHz}$, our new result is within $1 \mathrm{~K}$ of both the Liebe and the Stogryn models. At $85.5 \mathrm{GHz}$, we are in very good agreement with Liebe at all temperatures and at high temperatures also with Stogryn. In cold water, the surface-emitted brightness temperatures of the Stogryn models are about $2 \mathrm{~K}$ smaller than ours. The differences between our new fit and the models of Liebe and Stogryn in cold water increase to about $3 \mathrm{~K}$ at $170 \mathrm{GHz}$. We have checked that at higher frequencies the discrepancies between the Stogryn model and our new fit are decreasing. Above $260 \mathrm{GHz}$, the emitted brightness temperatures of our fit are within $1 \mathrm{~K}$ of the Stogryn model over the whole temperature range. It is also obvious that the single Debye models (Klein-Swift and Wentz) predict both much larger emissivities over cold water at $170 \mathrm{GHz}$ than Liebe, Stogryn, or our new fit.

The estimates of Wang [8] for emissivities of cold, fresh water, which are based on near nadir MIR airborne measurements over the Great Lakes at 89 and $220 \mathrm{GHz}$, seem to slightly favor the Stogryn model over Liebe's. At $150 \mathrm{GHz}$, all of the model emissivity predictions are by at least $3 \mathrm{~K}$ larger than Wang's data if he is using the Rosenkranz 1998 water vapor absorption for retrieving. Wang also states that the $\varepsilon$ value of Guillou et al. [7] at $89 \mathrm{GHz}$ and low temperatures is inconsistent with his measurements. This differs from our observation in Section II, which found that Guillou's value provided the best fit for the SSM/I ocean brightness temperatures at $85.5 \mathrm{GHz}$. It should be noted that Wang's data are all taken over cold water whose temperature is close to freezing, and it is, therefore, difficult to analyze the temperature behavior of the emissivity model as we did in Fig. 1. Clearly, more measurements of the fresh water emissivity at high frequency would be needed to resolve these inconsistencies and validate one of the models.

\section{Implications for Liquid Cloud Water Absorption}

In order to assess the implications of our new fit for the liquid cloud water absorption, we have repeated the SSM/I 
TABLE IV

$\sqrt{Q^{2}}$ BETWEEN EXPERIMENTAL DATASETS AND VARIOUS FITS FOR THE DIELECTRIC CONSTANT OF PURE WATER

\begin{tabular}{c|c|c|c|c|c}
\hline & Liebe et al. [12] & Stogryn et al. [13] & Wentz [10, 11] & Klein-Swift [1] & NEW FIT \\
\hline Barthel et al. [40] & 0.63 & 0.56 & 0.70 & 0.76 & 0.57 \\
\hline Kaatze et al. [38] & 0.29 & 0.57 & 0.63 & 0.58 & 0.36 \\
\hline Bertolini et al. [36] & 1.59 & 3.22 & 2.44 & 1.59 & 0.68 \\
\hline Hasted et al. [39] & 0.32 & 0.31 & 0.72 & 0.71 & 0.29 \\
\hline
\end{tabular}
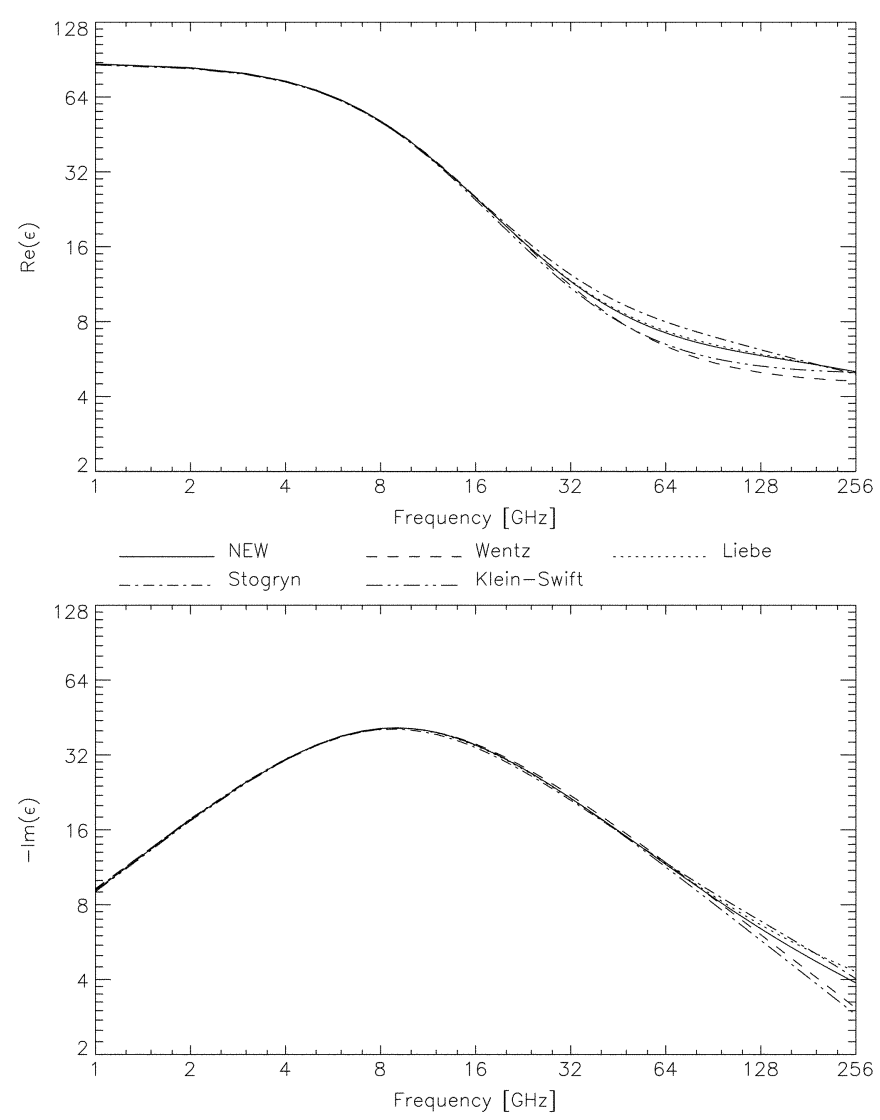

Fig. 3. Real and imaginary part of the dielectric constant for pure water with a temperature of $0{ }^{\circ} \mathrm{C}$ as function of frequency for various dielectric models.

brightness temperature analysis for cold clouds and included columnar cloud water contents up to $0.18 \mathrm{~mm}$. We have limited the columnar water vapor to below $40 \mathrm{~mm}$ in order to avoid possible uncertainties, which could arise from deficiencies in the vapor absorption model or errors in the vapor retrievals. We have binned the difference between measured and RTM brightness temperatures $T_{\mathrm{B}}-F$ with respect to the total cloud water $L$ as well as the average temperature $T_{\text {cloud }}$ of the liquid cloud, which we have obtained from the NCEP profiles. The population in the temperature bins ranges from 2000 at $T_{\text {cloud }}=-15{ }^{\circ} \mathrm{C}$ to over 90000 at $T_{\text {cloud }}=+6{ }^{\circ} \mathrm{C}$. The population in the cloud water bins ranges from 2000 at $L=$ $0.18 \mathrm{~mm}$ to over 280000 at $L=0.02 \mathrm{~mm}$. Fig. 9 shows the results at $85.5 \mathrm{GHz}$. Because we want to test the influence of $\varepsilon$ on the cloud water absorption and not the surface emissivity, we have used the emissivity model of Guillou et al. [7] for all four curves. We had shown in Section II-B that this model provides the best results for the ocean surface emissivity at $85.5 \mathrm{GHz}$.

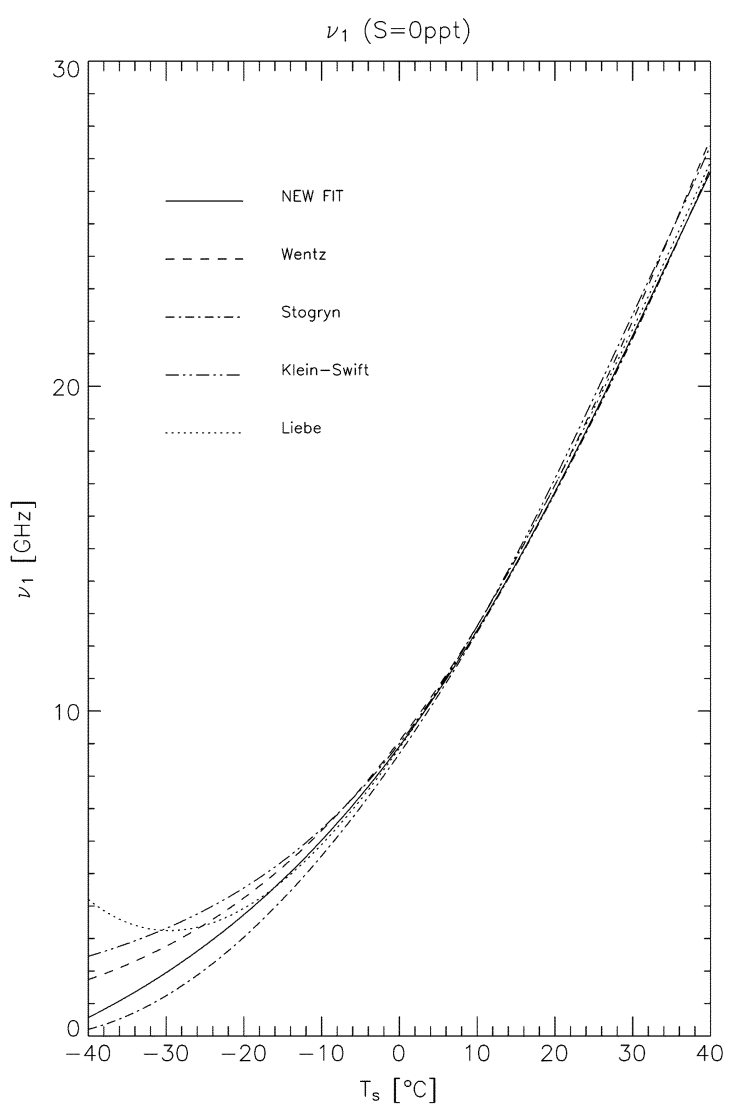

Fig. 4. First Debye relaxation frequency $\nu_{1}$ of pure water as function of surface temperature for various dielectric models.

It is obvious that the liquid cloud water absorption (2) is less sensitive to the value of the dielectric constant than the surface emissivity (1). Our new fit gives an absorption very close to the one predicted by Liebe's model. The plot also suggests that the cloud water absorption obtained by the dielectric model of Stogryn is getting too small as the cloud water temperature decreases. The absorption using the Wentz model is slightly larger than with our new model but the overall temperature dependence is almost the same. We have also checked that at $37 \mathrm{GHz}$ the four curves differ by less than $0.35 \mathrm{~K}$ over the whole range of $T_{\text {cloud }}$. Though neither Liebe et al. nor Wentz had included data for supercooled water in their fits for $\varepsilon$, we can conclude that their dielectric models perform nevertheless very well for frequencies below $100 \mathrm{GHz}$ and average cloud temperatures above $-20{ }^{\circ} \mathrm{C}$. The discrepancies between the models for cloud water absorption can get very large at lower temperatures due to the very different analytic forms of the model constants and the fact that no laboratory data exist for those low temperatures [38]. The differences between 


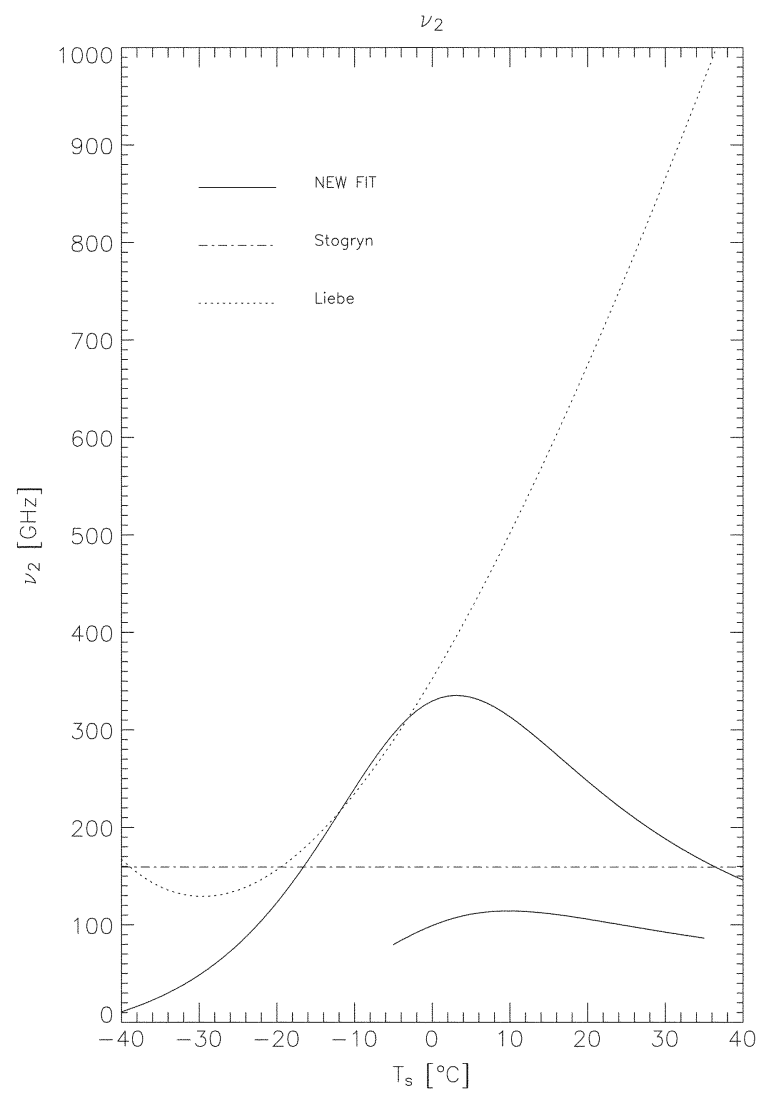

Fig. 5. Second Debye relaxation frequency $\nu_{2}$ as a function of surface temperature for various dielectric models. The long segments correspond to pure water and the short segments to sea water with a salinity of $35 \mathrm{ppt}$. The model of [13] has no salinity dependence, and the model of [12] is for pure water only.

the various model predictions for supercooled cloud water absorption also increases with increasing frequency [38]. In the absence of any reliable cloud water absorption measurements in these cases, it is currently not possible to perform a better validation.

It should also be noted the cloud water absorption that at 37 and $85.5 \mathrm{GHz}$ is mainly sensitive to the real part of the dielectric constant and almost insensitive to its imaginary part. For $T_{\text {cloud }}=-10{ }^{\circ} \mathrm{C}$, an increase of $\operatorname{Re}(\varepsilon)$ by $10 \%$ decreases the total cloud water absorption by about $8 \%$, whereas an increase of $\operatorname{Im}(\varepsilon)$ by $10 \%$ increases the total cloud absorption by only $0.7 \%$. As we will discuss in further detail in the next section, the surface emissivity is mainly sensitive to $\operatorname{Im}(\varepsilon)$, especially at higher frequencies. This means that surface emissivity and cloud water absorption probe in fact different parts of the dielectric constant.

\section{Dielectric Constant of Sea Water}

As a final step, we now proceed to the fit for the dielectric constant of sea water based on the ocean surface emissivity analysis from Section II. The double Debye relaxation law (6) requires to determine the temperature and salinity dependence of the six parameters $\varepsilon_{\mathrm{S}}(T, S), \varepsilon_{1}(T, S), \varepsilon_{\infty}(T, S)$, $\nu_{1}(T, S), \nu_{2}(T, S)$, and $\sigma(T, S)$ with the constraints (7) and (8) at $S=0$.

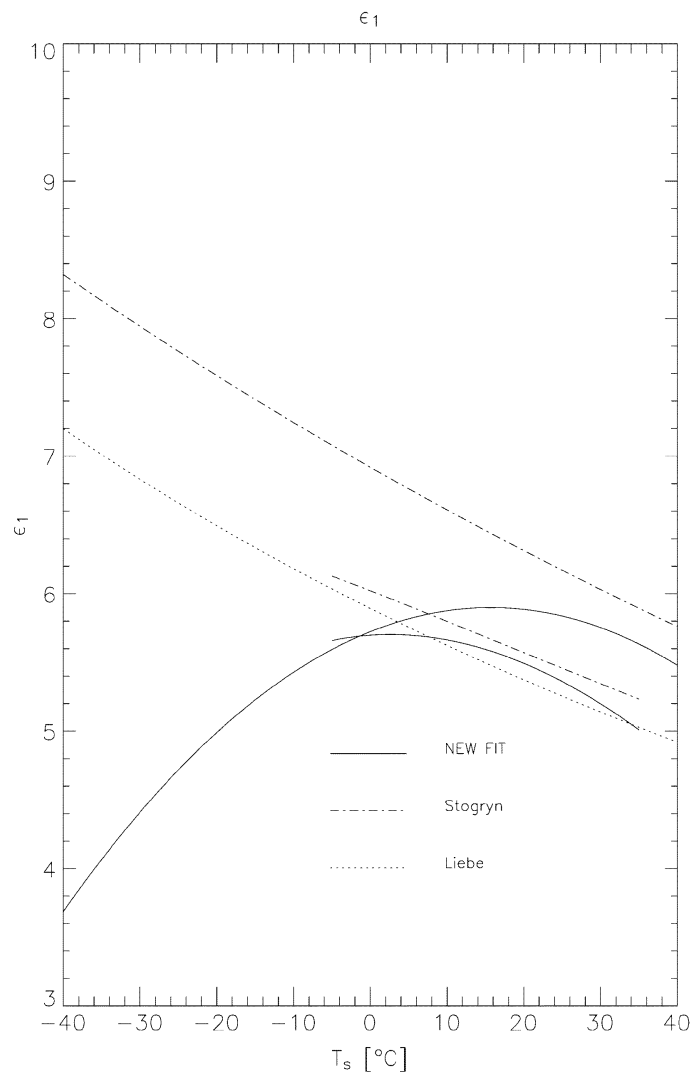

Fig. 6. Parameter $\varepsilon_{1}$ as function of surface temperature for various dielectric models. The long segments correspond to pure water, and the short segments to sea water with a salinity of $35 \mathrm{ppt}$.

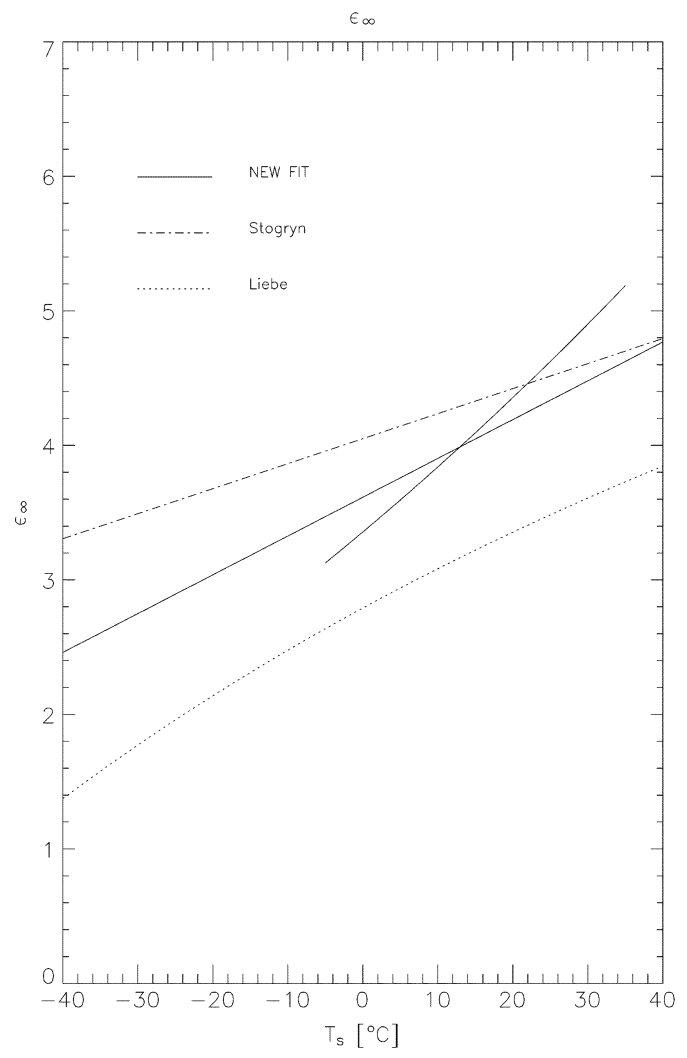

Fig. 7. Parameter $\varepsilon_{\infty}$ as function of surface temperature for various dielectric models. The long segments correspond to pure water and the short segments to sea water with a salinity of $35 \mathrm{ppt}$. The model of [13] has no salinity dependence, and the model of [12] is for pure water only. 

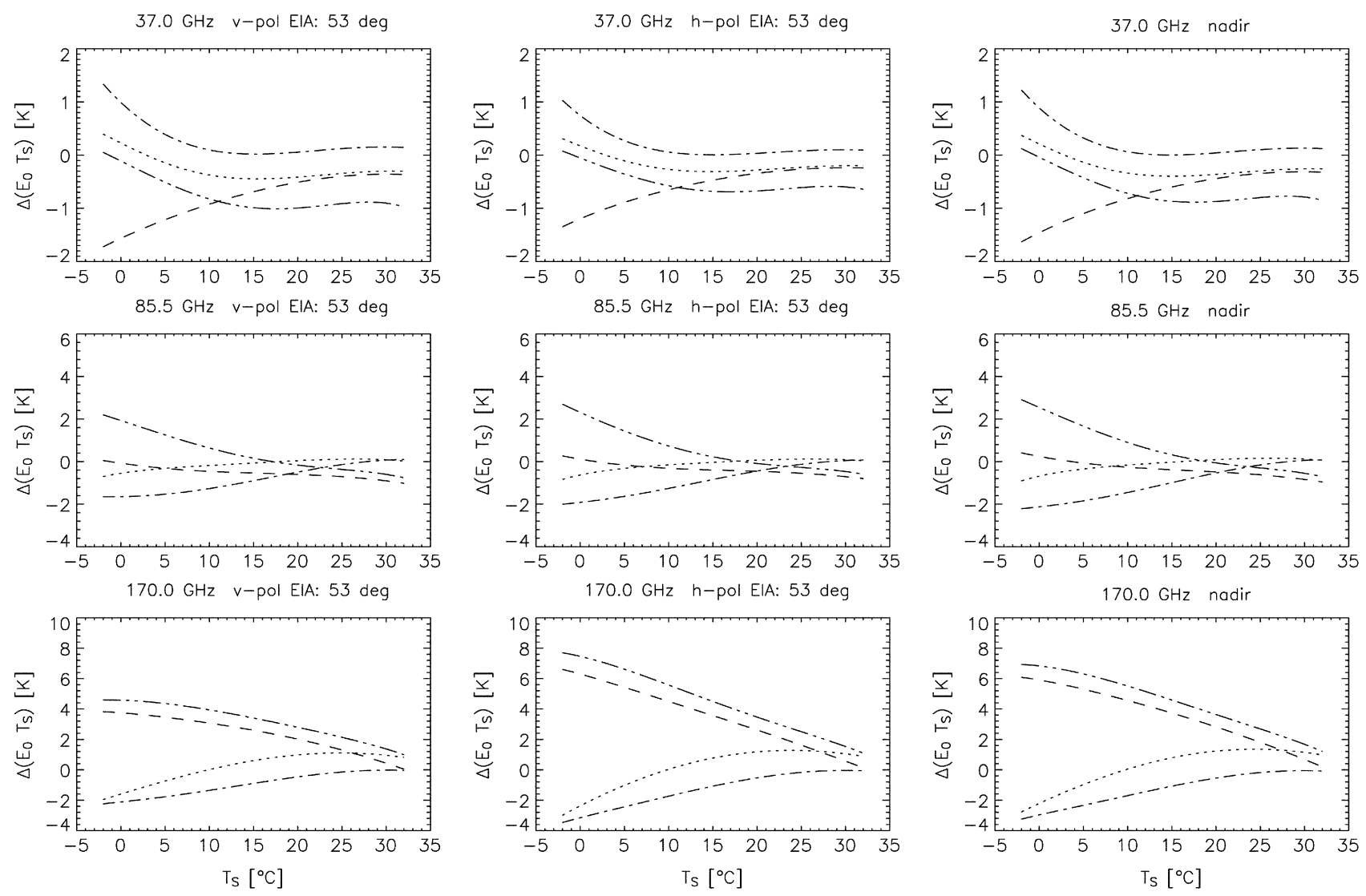

Fig. 8. Surface-emitted brightness temperature, defined as product of surface emissivity and surface temperature (in kelvin) for pure water. The plot shows the differences between various models and our new result as a function of surface temperature: Wentz [11] (dashed line), Stogryn [13] (dashed-dotted line), Klein-Swift [1] (dashed-dotted-dotted line), and Liebe [12] (dotted line).

\section{A. Conductivity of Sea Water}

The conductivity of sea water $\sigma(T, S)$ has been measured in laboratory experiments. We use the most updated regression given in [13], which we repeat for reference here. In the relevant salinity range $20 \mathrm{ppt} \leq S \leq 40 \mathrm{ppt}$, it differs by less than $0.5 \%$ from the expression given by Wentz [11]

$$
\sigma(T, S)=\sigma(T, S=35) \cdot R_{15}(S) \cdot \frac{R_{T}(S)}{R_{15}(S)}
$$

where

$$
\begin{aligned}
\sigma(T, S=35)= & 2.903602+8.607 \cdot 10^{-2} \cdot T+4.738817 \cdot 10^{-4} \\
& \cdot T^{2}-2.991 \cdot 10^{-6} \cdot T^{3}+4.3047 \cdot 10^{-9} \cdot T^{4} \\
R_{15}(S)= & S \cdot \frac{\left(37.5109+5.45216 \cdot S+1.4409 \cdot 10^{-2} \cdot S^{2}\right)}{\left(1004.75+182.283 \cdot S+S^{2}\right)} \\
\frac{R_{T}(S)}{R_{15}(S)}= & 1+\frac{\alpha_{0}(T-15)}{\left(\alpha_{1}+T\right)} \\
\alpha_{0}= & \frac{\left(6.9431+3.2841 \cdot S-9.9486 \cdot 10^{-2} \cdot S^{2}\right)}{\left(84.850+69.024 \cdot S+S^{2}\right)} \\
\alpha_{1}= & 49.843-0.2276 \cdot S+0.198 \cdot 10^{-2} \cdot S^{2} .
\end{aligned}
$$

The units are $T$ (degrees centigrade), $S$ (parts per thousand), and $\sigma$ (siemens per meter).

\section{B. Fit Ansatz,}

For the remaining five constants, we make the ansatz

$$
\begin{aligned}
\varepsilon_{\mathrm{S}}(T, S) & =\varepsilon_{\mathrm{S}}(T, S=0) \cdot \exp \left[b_{0} S+b_{1} S^{2}+b_{2} T S\right] \\
\nu_{1}(T, S) & =\nu_{1}(T, S=0) \cdot\left[1+S \cdot\left(b_{3}+b_{4} T+b_{5} T^{2}\right)\right] \\
\varepsilon_{1}(T, S) & =\varepsilon_{1}(T, S=0) \cdot \exp \left[b_{6} S+b_{7} S^{2}+b_{8} T S\right] \\
\nu_{2}(T, S) & =\nu_{2}(T, S=0) \cdot\left[1+S \cdot\left(b_{9}+b_{10} T\right)\right] \\
\varepsilon_{\infty}(T, S) & =\varepsilon_{\infty}(T, S=0) \cdot\left[1+S \cdot\left(b_{11}+b_{12} T\right)\right] .
\end{aligned}
$$

Other than in earlier models, we have also allowed a salinity dependence for $\varepsilon_{\infty}$.

The 13 fit parameters $b_{i}, i=0, \ldots, 12$ are again determined by minimizing the square deviation (10) between data and fit function (6)-(8) for real and imaginary parts of the dielectric constant.

\section{Metadata and Weights}

For performing the minimization, we create a metadataset, which will allow us to obtain a value for the surface emissivity from our fit that is consistent with results of the SSM/I brightness temperature analysis in Section II. For frequencies up to $37 \mathrm{GHz}$, we want to be as close as possible to the model of Wentz [11] and at $85.5 \mathrm{GHz}$ to the value of Guillou et al. [7].

It is important to note that the sensitivity of the specular emissivity $E_{0}$ to $\operatorname{Im}(\varepsilon)$ is much stronger than to $\operatorname{Re}(\varepsilon)$, and this 

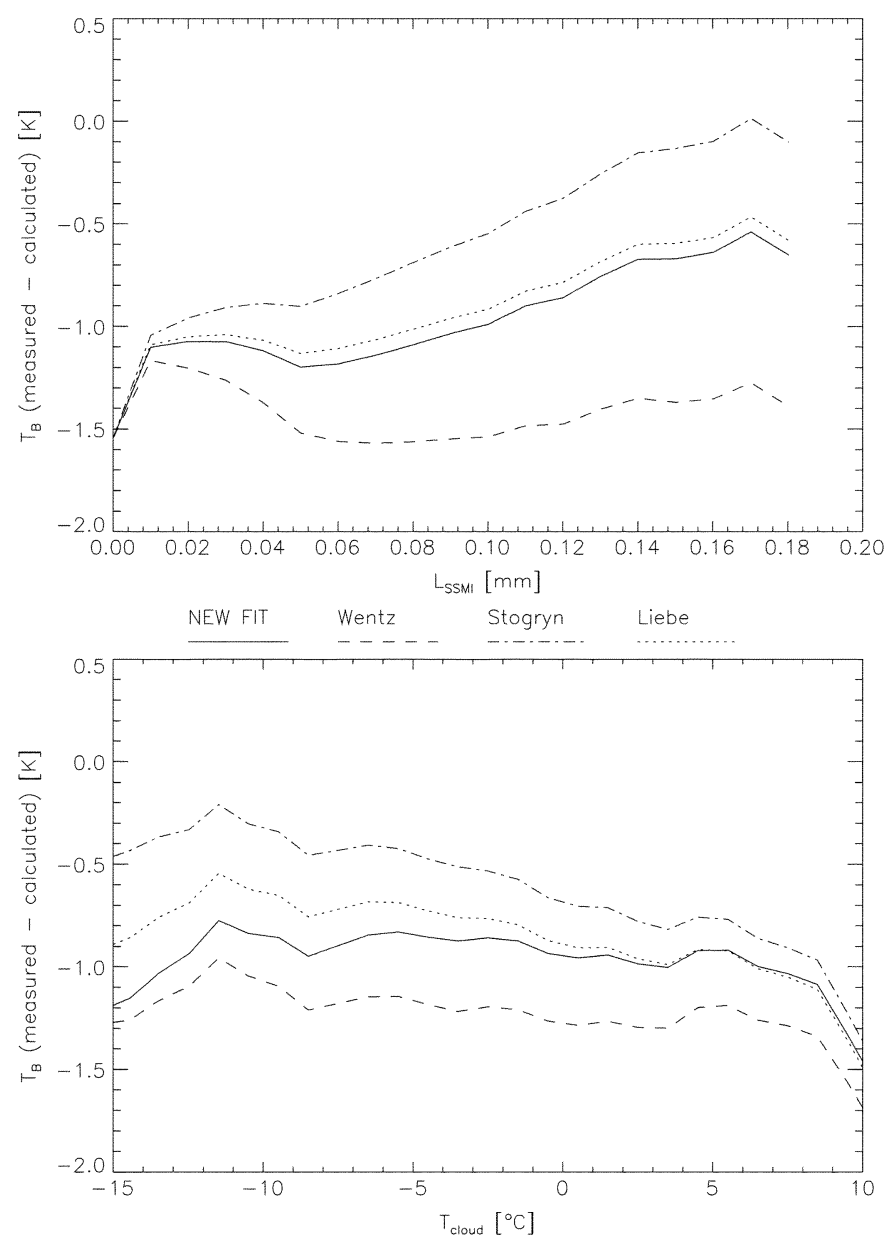

Fig. 9. SSM/I measured minus computed 85.5-GHz v-pol ocean brightness temperatures as a function of columnar liquid cloud water (bin size $0.01 \mathrm{~mm}$ ) and average cloud temperature (bin size $1 \mathrm{~K}$ ) for cold clouds using various models for the cloud water dielectric constant.

TABLE $\mathrm{V}$

SENSITIVITY OF THE SURFACE-EMITTED BRIGHTNESS TEMPERATURE $E_{0} T_{\mathrm{S}}$ TO ReAl AND IMAGINARY PART OF THE Dielectric Constant AT $T=0^{\circ} \mathrm{C}$

\begin{tabular}{c|c|c}
\hline$v[G H z]$ & $\left.\frac{\Delta\left(E_{0} T_{S}\right)}{\Delta \operatorname{Re}(\varepsilon)}\right|_{T_{s}=273.15 K}[K]$ & $\left.\frac{\Delta\left(E_{0} T_{S}\right)}{\Delta \operatorname{Im}(\varepsilon)}\right|_{T_{s}=273.15 K}[K]$ \\
\hline 19.35 & -0.056 & +1.571 \\
\hline 37.0 & +0.300 & -2.705 \\
\hline 85.5 & +0.082 & +4.470 \\
\hline
\end{tabular}

discrepancy increases with increasing frequency (cf. Table V). From this, it follows that at higher frequencies $(37 \mathrm{GHz}$ and especially $85.5 \mathrm{GHz}$ ) the result in Section II allows us mainly to pin down $\operatorname{Im}(\varepsilon)$, whereas larger deviations of $\operatorname{Re}(\varepsilon)$ between the final fit and metadata are allowed without changing the value of the surface emissivity. This fact provides us with an important guideline for choosing appropriate weights $w_{i}^{1}$ and $w_{i}^{2}$ in (10). The final choice of the metadataset and the weights is done by trial and error so that the final result matches our objective best. The choice of the metadata and their weights are as follows.

1) The frequencies of the metadata points are taken at 1.4, 7.0, 10.0, 18.0, 24.0, 37.0, 85.5, and 89.0 GHz.
TABLE VI

PARAMETERS OF THE FIT (17) FOR SEA WATER

\begin{tabular}{|c|c|}
\hline$i$ & $b_{i}$ \\
\hline 0 & $-3.56417 \mathrm{E}-03$ \\
\hline 1 & $4.74868 \mathrm{E}-06$ \\
\hline 2 & $1.15574 \mathrm{E}-05$ \\
\hline 3 & $2.39357 \mathrm{E}-03$ \\
\hline 4 & $-3.13530 \mathrm{E}-05$ \\
\hline 5 & $2.52477 \mathrm{E}-07$ \\
\hline 6 & $-6.28908 \mathrm{E}-03$ \\
\hline 7 & $1.76032 \mathrm{E}-04$ \\
\hline 8 & $-9.22144 \mathrm{E}-05$ \\
\hline 9 & $-1.99723 \mathrm{E}-02$ \\
\hline 10 & $1.81176 \mathrm{E}-04$ \\
\hline 11 & $-2.04265 \mathrm{E}-03$ \\
\hline 12 & $1.57883 \mathrm{E}-04$ \\
\hline
\end{tabular}

2) For each frequency, we chose the following values for surface temperature: $-2{ }^{\circ} \mathrm{C},+12^{\circ} \mathrm{C},+20^{\circ} \mathrm{C}$, and $+30^{\circ} \mathrm{C}$.

3) For $37 \mathrm{GHz}$ and below, we chose the following values for salinity: 10, 20, 30, 35, and 40 ppt. The values of $\varepsilon$ are computed using the Wentz [11] model.

4) At 85.5 and $89.0 \mathrm{GHz}$, we have set the salinity to $35 \mathrm{ppt}$ and taken the values of $\varepsilon$ given by Guillou et al. [7]. These data do not allow a study of the salinity dependence of $\varepsilon$. As a consequence, in our ansatz (17), we have fitted the constants $\nu_{2}$ and $\varepsilon_{\infty}$, which govern the high-frequency behavior of $\varepsilon$, only with a linear salinity dependence.

5) For each value of frequency and temperature, we have supplemented the dataset with an $\varepsilon$ for pure water $(S=0)$ using our new fit from Section III.

6) We are using the weights $w_{i}^{1}=w_{i}^{2}=1$ for $\nu \leq 24 \mathrm{GHz}$, $w_{i}^{1}=1$ and $w_{i}^{2}=5$ for $\nu=37 \mathrm{GHz}$, and $w_{i}^{1}=0$ and $w_{i}^{2}=10$ for $\nu \geq 85.5 \mathrm{GHz}$.

The choices 3) and 5) imply that we have not used the values for $\operatorname{Re}(\varepsilon)$ from [7], but strongly weighted their values for $\operatorname{Im}(\varepsilon)$ instead. The reason for this choice is the fact that $E_{0} T_{\mathrm{S}}$ is much less sensitive to $\operatorname{Re}(\varepsilon)$ than to $\operatorname{Im}(\varepsilon)$, as mentioned earlier. Moreover, the values for $\operatorname{Re}(\varepsilon)$ at 85.5 and $89.0 \mathrm{GHz}$ given in [7] differ by $10 \%$, which is obviously too large. This points to some potential uncertainty in their measurement of $\operatorname{Re}(\varepsilon)$. We have, therefore, decided to choose the weights at 85.5 and $89.0 \mathrm{GHz}$ in a way to ensure an optimal fit for $E_{0} T_{\mathrm{S}}$ rather than for $\operatorname{Re}(\varepsilon)$.

\section{Results}

Minimizing the value of $Q^{2}$ between this metadataset and the fit function leads to the values for the fit parameters $b_{i}, i=$ $0, \ldots, 12$ listed in Table VI. Fig. 10 shows the final result for $\operatorname{Re}(\varepsilon)$ and $\operatorname{Im}(\varepsilon)$ as a function of frequency at $T_{\mathrm{S}}=0{ }^{\circ} \mathrm{C}$ and $S=35$ ppt that we obtain from our fit and compares with the results of the other models. The discrepancy between the values of $\operatorname{Re}(\varepsilon)$ in our fit and the measurements of Guillou et al. [7] at 85.5 and $89 \mathrm{GHz}$ for saline water is due to the fact that we have not included their measurements in our fit data for the reasons 

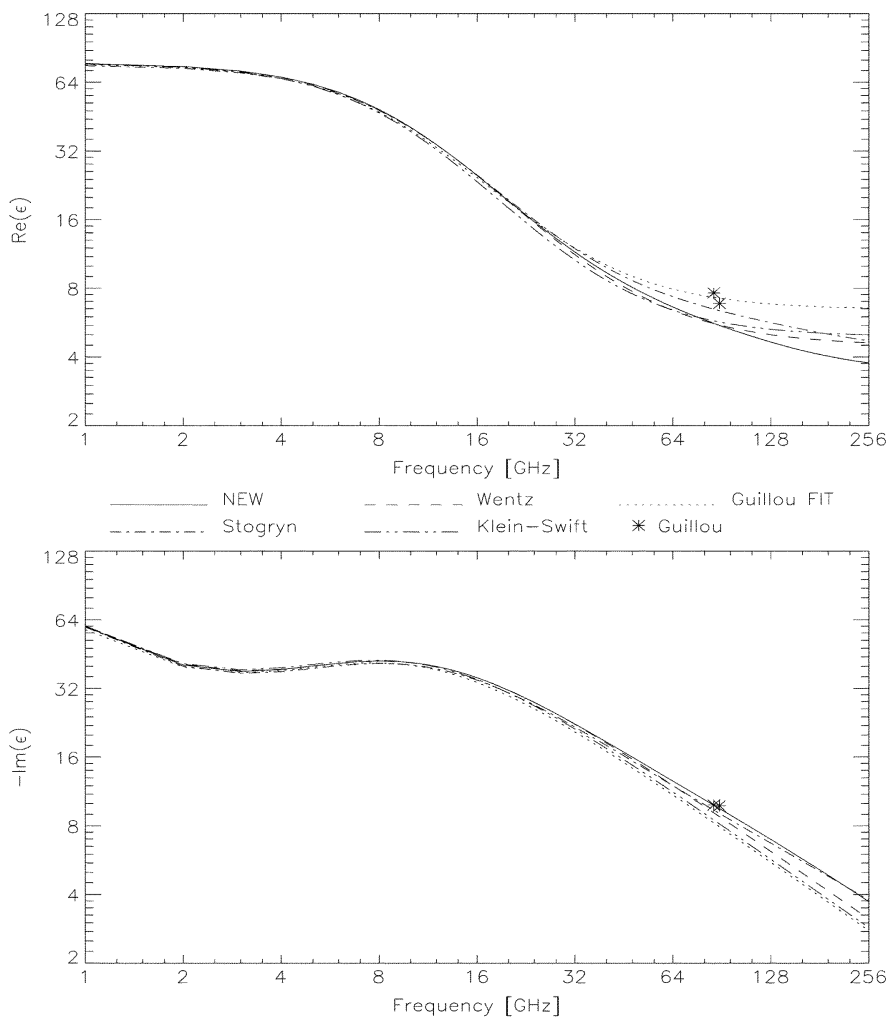

Fig. 10. Real and imaginary part of the dielectric constant for sea water with a salinity of $35 \mathrm{ppt}$ and a temperature of $0^{\circ}$ as function of frequency for various dielectric models. The star symbol corresponds to the measured values in [7], and the dotted line to their single Debye fit at low frequencies.

stated above. Our emissivity analysis of ocean emitted brightness temperatures can neither validate nor invalidate these measurements, and we cannot make an assessment about the quality of our fit for $\operatorname{Re}(\varepsilon)$ or any quantity that is sensitive to $\operatorname{Re}(\varepsilon)$ at frequencies above $37 \mathrm{GHz}$. The temperature dependences of the static dielectric constant $\varepsilon_{\mathrm{S}}$ and the first Debye relaxation frequency $\nu_{1}$ at $S=35 \mathrm{ppt}$ are displayed in Figs. 11 and 12, respectively. The short segments in Figs. 5-7, respectively, show the temperature dependence of the parameters $\nu_{2}, \varepsilon_{1}$, and $\varepsilon_{\infty}$ at $S=35$ ppt.

\section{E. Implications for the Specular Emissivity of Sea Water}

Most important for our purposes are the implications of our new fit for the ocean surface emissivities. From the values in Table I and the curves in Figs. 1 and 2, we anticipate that for the SSM/I v-pol brightness temperatures our new fit is matching the results of Wentz below $37 \mathrm{GHz}$ and the results of Guillou et al. [7] at $85.5 \mathrm{GHz}$ very accurately. In Table VII, we quote the values for the differences of $E_{0}\left(T_{\mathrm{S}}, S=35\right) \cdot T_{\mathrm{S}}$ between [11] and our new fit at low frequencies, between [7] and our new fit at $85.5 \mathrm{GHz}$, and between [13] and our new fit at $170 \mathrm{GHz}$. We consider v-pol and h-pol at $53^{\circ}$ EIA as well as nadir observations and use four values for SST. We see that the agreement with the Wentz model at low frequencies and the Guillou value at $85.5 \mathrm{GHz}$ also holds for $53^{\circ}$ EIA h-pol and for nadir observations. At $170 \mathrm{GHz}$, our new model agrees well with the predictions of Stogryn. Currently, there are neither laboratory measurements nor microwave sensor observations for the dielectric constant of sea water available at frequencies above $90 \mathrm{GHz}$.

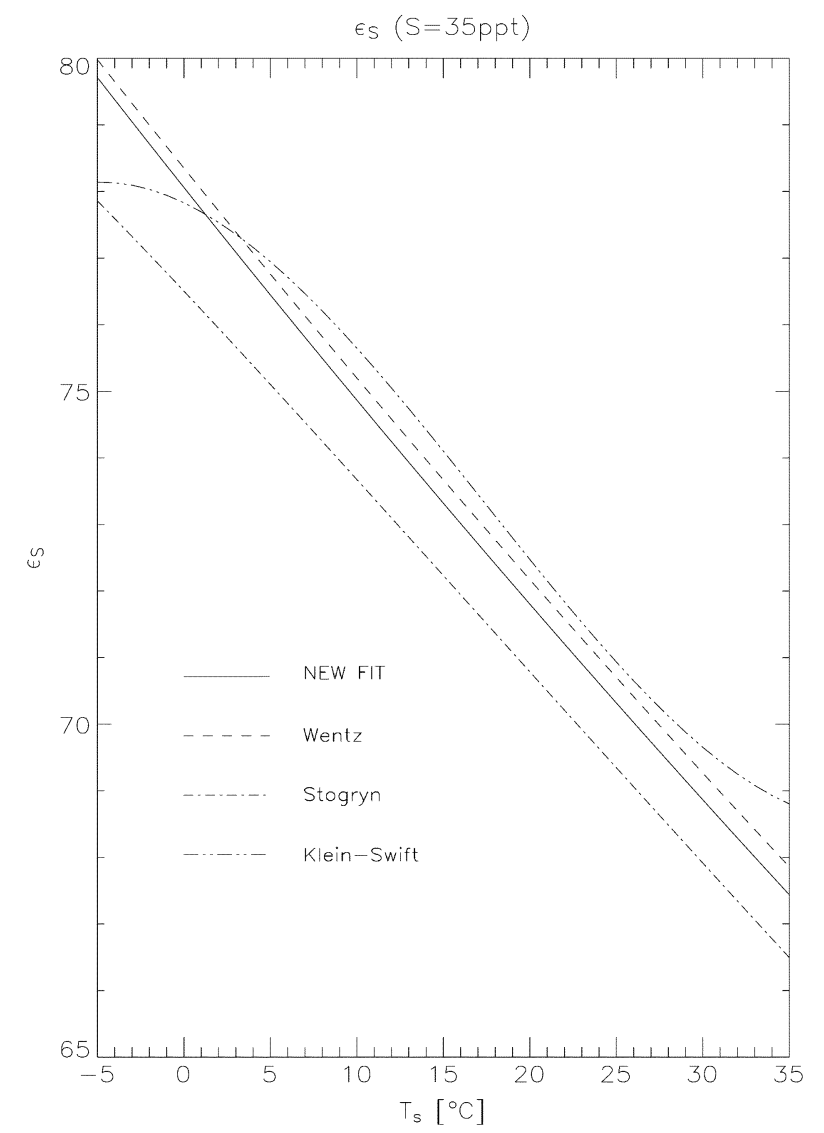

Fig. 11. Static dielectric constant $\varepsilon_{\mathrm{S}}$ of sea water with a salinity of $35 \mathrm{ppt}$ as function of surface temperature for various dielectric models.

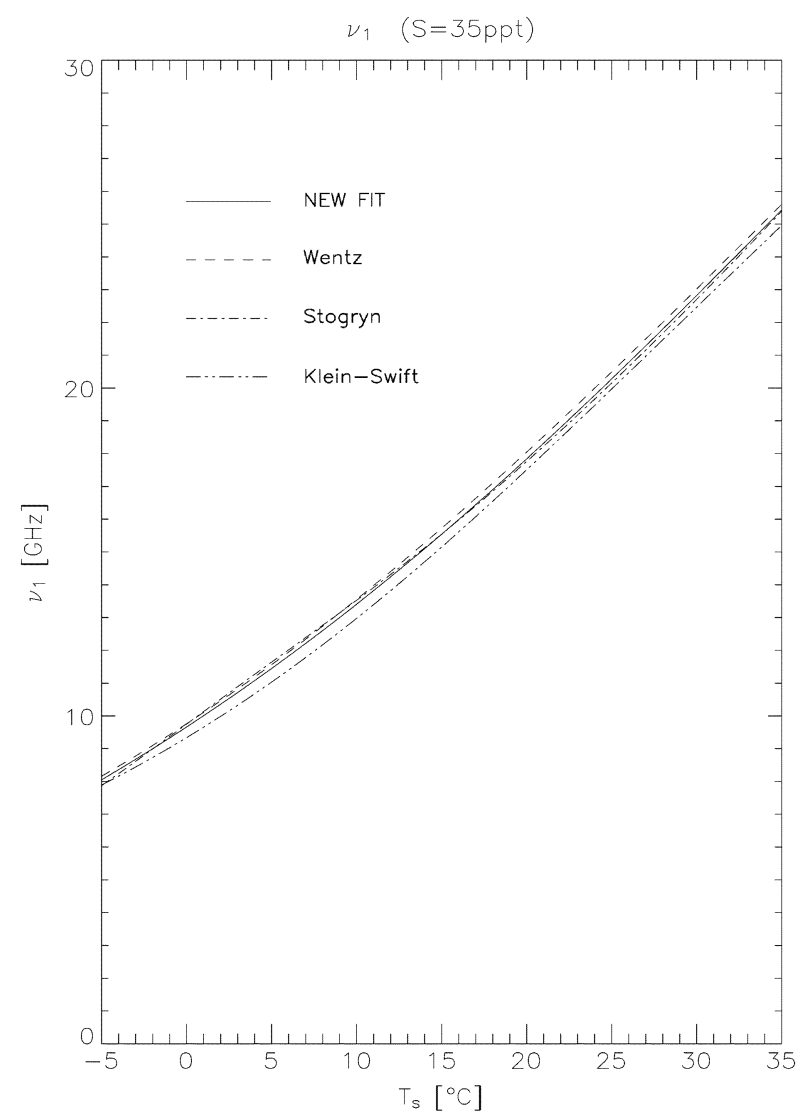

Fig. 12. First Debye relaxation frequency $\nu_{1}$ of sea water with a salinity of $35 \mathrm{ppt}$ as function of surface temperature for various dielectric models. 
TABLE VII

DifFERENCE OF THE SEA SURFACE EMITTED BRIGHTNESS TEMPERATURES (IN KELVIN) AT $53^{\circ}$ EIA v- AND h-POL AND NADIR BETWEEN VARIOUS MODELS AND OUR NEW FIT AT SEVERAL FREQUENCIES AND FOR FOUR VALUES OF SST

\begin{tabular}{|c|c|c|c|c|c|c|}
\hline Frequency [GHz] & MODEL - NEW FIT & $\mathrm{EIA} / \mathrm{POL}$ & $0^{\circ} \mathrm{C}$ & $10^{\circ} \mathrm{C}$ & $20^{\circ} \mathrm{C}$ & $30^{\circ} \mathrm{C}$ \\
\hline \multirow[t]{3}{*}{1.4} & WENTZ - NEW FIT & $53 \mathrm{deg} / \mathrm{v}-\mathrm{pol}$ & -0.15 & -0.17 & -0.15 & -0.13 \\
\hline & & $53 \mathrm{deg} / \mathrm{h}-\mathrm{pol}$ & -0.08 & -0.09 & -0.08 & -0.07 \\
\hline & & nadir & -0.12 & -0.13 & -0.12 & -0.10 \\
\hline \multirow[t]{3}{*}{6.9} & WENTZ - NEW FIT & $53 \mathrm{deg} / \mathrm{v}-\mathrm{pol}$ & 0.16 & 0.09 & 0.01 & -0.09 \\
\hline & & $53 \mathrm{deg} / \mathrm{h}-\mathrm{pol}$ & 0.09 & 0.05 & 0.00 & -0.05 \\
\hline & & nadir & 0.13 & 0.07 & 0.01 & -0.07 \\
\hline \multirow[t]{3}{*}{10.7} & WENTZ - NEW FIT & $53 \mathrm{deg} / \mathrm{v}-\mathrm{pol}$ & 0.12 & 0.13 & 0.10 & 0.03 \\
\hline & & $53 \mathrm{deg} / \mathrm{h}-\mathrm{pol}$ & 0.07 & 0.08 & 0.06 & 0.02 \\
\hline & & nadir & 0.10 & 0.10 & 0.08 & 0.02 \\
\hline \multirow[t]{3}{*}{18.7} & WENTZ - NEW FIT & $53 \mathrm{deg} / \mathrm{v}-\mathrm{pol}$ & -0.08 & -0.02 & 0.07 & 0.09 \\
\hline & & $53 \mathrm{deg} / \mathrm{h}-\mathrm{pol}$ & -0.05 & -0.01 & 0.04 & 0.05 \\
\hline & & nadir & -0.07 & -0.01 & 0.06 & 0.07 \\
\hline \multirow[t]{3}{*}{37.0} & WENTZ - NEW FIT & $53 \mathrm{deg} / \mathrm{v}-\mathrm{pol}$ & 0.23 & -0.23 & -0.25 & -0.22 \\
\hline & & $53 \mathrm{deg} / \mathrm{h}-\mathrm{pol}$ & 0.20 & -0.16 & -0.17 & -0.15 \\
\hline & & nadir & 0.25 & -0.20 & -0.23 & -0.20 \\
\hline \multirow[t]{3}{*}{85.5} & GUILLOU - NEW FIT & $53 \mathrm{deg} / \mathrm{v}-\mathrm{pol}$ & 0.24 & 0.28 & 0.67 & 0.32 \\
\hline & & $53 \mathrm{deg} / \mathrm{h}-\mathrm{pol}$ & -0.11 & 0.04 & 0.44 & 0.19 \\
\hline & & nadir & -0.35 & -0.12 & 0.41 & 0.17 \\
\hline \multirow[t]{3}{*}{170.0} & STOGRYN - NEW FIT & $53 \mathrm{deg} / \mathrm{v}-\mathrm{pol}$ & 0.19 & 0.64 & 0.48 & -0.30 \\
\hline & & $53 \mathrm{deg} / \mathrm{h}-\mathrm{pol}$ & -0.29 & 0.61 & 0.49 & -0.32 \\
\hline & & nadir & -0.56 & 0.47 & 0.46 & -0.33 \\
\hline
\end{tabular}

\section{SUMMARY AND CONCLUSION}

The main issue of this study was to provide an updated fit for the dielectric constant of pure and sea water that can be used in the theory of radiative transfer of ocean-emitted microwave radiation and is valid within a larger frequency and temperature range than the model of Klein-Swift, which has been mainly used so far. Our new fit uses two Debye relaxation frequencies: the lower one at around $20 \mathrm{GHz}$ and the upper one, which lies roughly between 100-300 GHz. For sea water, our new model is consistent with the model of Wentz [11] below $37 \mathrm{GHz}$ and with the measurements of $\operatorname{Im}(\varepsilon)$ by Guillou et al. [7] at 85.5 and $89 \mathrm{GHz}$. For pure water, we have used a large dataset of laboratory measurements in the frequency range up to $500 \mathrm{GHz}$ and in the temperature range between $-20{ }^{\circ} \mathrm{C}$ and $+40{ }^{\circ} \mathrm{C}$, which includes supercooled water. Our fit smoothly interpolates the dielectric constant as a function of salinity between 0-40 ppt.

We have validated our new model using an analysis of the four SSM/I v-pol channels (19.35, 22.235, 37.0, and $85.5 \mathrm{GHz})$. We have shown that for these channels our dielectric model gives very accurate values for the ocean surface emissivities between $-2{ }^{\circ} \mathrm{C}$ and $+29^{\circ} \mathrm{C}$ as well as the liquid cloud water absorption above $-15^{\circ} \mathrm{C}$. Due to the lack of measurements, uncertainties still remain in other cases.

\section{ACKNOWLEDGMENT}

The authors thank P. Rosenkranz (MIT) for the Fortran codes for calculating the water vapor [24] and oxygen absorption coefficients and to J. Wang (NASA Goddard) for the Fortran code of the dielectric model [13].

\section{REFERENCES}

[1] L. A. Klein and C. T. Swift, "An improved model for the dielectric constant of sea water at microwave frequencies," IEEE J. Oceanic Eng., vol. OE-2, pp. 104-111, 1977.

[2] P. Debye, Polar Molecules. New York: Chemical Catalog, 1929.

[3] K. S. Cole and R. H. Cole, "Dispersion and absorption in dielectrics," $J$. Chem. Phys., vol. 9, pp. 341-351, 1941

[4] J. A. Lane and J. A. Saxton, "Dielectric dispersion in pure polar liquids at very high frequencies, III: The effect of electrolytes in solution," in Proc. R. Soc., vol. A213, 1952, pp. 531-545.
[5] W. Ho and W. F. Hall, "Measurements of the dielectric properties of sea water and $\mathrm{NaCl}$ solutions at $2.65 \mathrm{GHz}$," J. Geophys. Res., vol. 78, pp. 6301-6315, 1973.

[6] W. W. Ho, A. W. Love, and M. J. V. Melle, "Measurements of the dielectric properties of sea water at $1.43 \mathrm{GHz}$," NASA, Greenbelt, MD, NASA Contractor Rep. CR-2458, 1974.

[7] C. Guillou et al., "Impact of new permittivity measurements on sea surface emissivity modeling in microwaves," Radio Sci., vol. 33, no. 3, pp. 649-667, 1998.

[8] J. R. Wang, "A comparison of the MIR-estimated and model-calculated fresh water surface emissivities at 89, 150, and $220 \mathrm{GHz}$," IEEE Trans. Geosci. Remote Sensing, vol. 40, pp. 1356-1365, June 2002.

[9] F. Wentz, "Measurement of oceanic wind vector using satellite microwave radiometers," IEEE Trans. Geosci. Remote Sensing, vol. 30, pp. 960-972, Sept. 1992.

[10] F. J. Wentz, "A well calibrated ocean algorithm for special sensor microwave/imager," J. Geophys. Res., vol. 102, no. C4, pp. 8703-8718, 1997.

[11] F. Wentz and T. Meissner, "AMSR ocean algorithm (version 2)," Remote Sens. Syst., Santa Rosa, CA, http://www.remss.com, 1999.

[12] H. J. Liebe, G. A. Hufford, and T. Manabe, "A model for the complex permittivity of water at frequencies below $1 \mathrm{THz}$," Int. J. Infr. Millim. Waves, vol. 12, no. 7, pp. 659-675, 1991.

[13] P. A. Stogryn et al., The Microwave Permittivity of Sea and Fresh Water. Azusa, CA: GenCorp Aerojet, 1995.

[14] W. Ellison et al., "New permittivity measurements of seawater," Radio Sci., vol. 33, no. 3, pp. 639-648, 1998.

[15] NOAA, World Ocean Atlas 1998 (WOA98). Silver Spring, MD: Ocean Climate Lab., Nat. Oceanograph. Data Center, 1999.

[16] A. Stogryn, "The apparent temperature of the sea at microwave frequencies," IEEE Trans. Antennas Propagat., vol. AP-15, pp. 278-286, 1967.

[17] — " "The emissivity of sea foam at microwave frequencies," J. Geophys. Res., vol. 77, pp. 1650-1666, 1972.

[18] T. T. Wilheit, "The effect of wind on the microwave emission from the ocean's surface at $37 \mathrm{GHz}$,' J. Geophys. Res., vol. 84, pp. 4921-4926, 1979.

[19] - "A model for the microwave emissivity of the ocean's surface as a function of wind speed," IEEE Trans. Gesoci. Electron., vol. GE-17, pp. 244-249, 1979.

[20] J. P. Hollinger, "Passive microwave measurements of sea surface roughness," IEEE Trans. Geosci. Electron., vol. GE-9, pp. 165-169, 1971.

[21] F. Wentz, "A two-scale scattering model for foam-free sea microwave brightness temperatures," J. Geophys. Res., vol. 80, pp. 3441-3446, 1975.

[22] — , "The dependence of sea-surface microwave emission on wind speed, frequency, incidence angle, and polarization over the frequency range from 1 to $40 \mathrm{GHz}$, IEEE Trans. Geosci. Remote Sensing, vol. GE-25, pp. 138-146, Mar. 1987.

[23] T. Meissner and F. Wentz, "A radiative transfer model function for 85.5 GHz SSM/I ocean brightness temperatures," Radio Sci., vol. 38, no. 4, pp. MAR 31-1-MAR 31-6, 2003.

[24] P. Rosenkranz, "Water vapor microwave continuum absorption: A comparison of measurements and models," Radio Sci., vol. 33, no. 4, pp. 919-928, 1998.

[25] T. Meissner and F. Wentz, Radiative Transfer Model Function From SSM/I Brightness Temperatures. Santa Rosa, CA: Remote Sens. Syst., 2003.

[26] H. J. Liebe, P. W. Rosenkranz, and G. A. Hufford, "Atmospheric 60-GHz oxygen spectrum: New laboratory measurements and line parameters," J. Quant. Spectrosc. Radiat. Transf., vol. 48, pp. 629-643, 1992.

[27] M. J. Schwartz, Observation and Modeling of Atmospheric Oxygen Millimeter-Wave Transmittance. Cambridge, MA: MIT, 1997.

[28] C. Malmberg and A. Maryott, "Dielectric constant of water from $0^{\circ}$ to $100^{\circ}$ C," J. Res. Nat. Bur. Stand., vol. 56, pp. 1-8, 1956.

[29] R. Kay, G. Vidulich, and K. Pribadi, "Reinvestigation of the dielectric constant of water and its temperate coefficient," J. Phys. Chem., vol. 73, p. $445,1969$.

[30] D. G. Archer and P. Wang, "The dielectric constant of water and DebyeHuckel limiting law slopes," J. Phys. Chem. Ref. Data, vol. 19, p. 371, 1990.

[31] Handbook of Chemistry and Physics, 74th ed., CRC, Ann Arbor, MI, 1993, pp. 6-10. D. R. Lide.

[32] E. Sharkov, Passive Microwave Remote Sensing of the Earth: Physical Foundations, ser. Springer Praxis Books in Geophysical Sciences. Berlin, Germany: Springer-Verlag, 2003.

[33] D. Bertolini, M. Cassettari, and G. Salvetti, "The dielectric relaxation time of supercooled water," J. Chem. Phys., vol. 76, no. 6, pp. 3285-3290, 1982. 
[34] C. A. Angell, "Supercooled water," in Water: A Comprehensive Treatise, F. Franks, Ed. New York: Plenum, 1982.

[35] U. Kaatze and V. Uhlendorf, "The dielectric properties of water at microwave frequencies," Zeitsch f Phys. Chem. Neue Folge, vol. 126, pp. $151-165,1981$.

[36] J. B. Hasted et al., "The temperature variation of the near millimeter wavelength optical constants of water," Infr. Phys., vol. 27, no. 1, pp. $11-15,1987$.

[37] J. Barthel et al., "A computer-controlled system of transmission lines for the determination of the complex permittivity of lossy liquids between 8.5 and $90 \mathrm{GHz}$," Ber. Bunsenges. Phys. Chem., vol. 95, no. 8, pp. 853-859, 1991

[38] A. Lipton, M. Griffin, and A. Ling, "Microwave transfer model differences in remote sensing of cloud liquid water at low temperatures," IEEE Trans. Geosci. Remote Sensing, vol. 37, pp. 620-323, Jan. 1999.

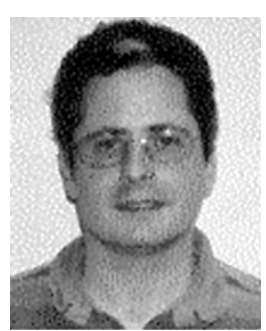

Thomas Meissner received the B.S. degree in physics from the University of Erlangen-Nürnberg, Nürnberg, Germany, in 1983, the M.S. degree (Diploma) in physics from the University of Bonn, Bonn, Germany, in 1987, and the Ph.D. degree in theoretical physics from the University of Bochum, Bochum, Germany, in 1991. He wrote his doctoral dissertation on effective quark models of the nucleon.

Between 1992 and 1998, he conducted postdoctoral research at the University of Washington, Seattle, the University of South Carolina, Columbia, and Carnegie Mellon University, Pittsburgh, PA, in theoretical nuclear and particle physics, focusing on the theory of strong interaction. Since July 1998, he has been with Remote Sensing Systems, Santa Rosa, CA. Since then, he has worked on calibration/validation for SSM/I and TMI, the development and refinement of radiative transfer models that relate satellite observations to geophysical parameters, and the development of a wind vector retrieval algorithm for CMIS.

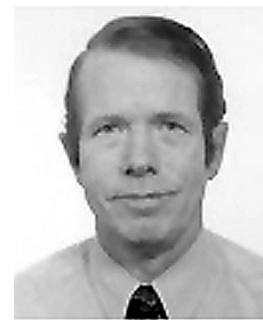

Frank J. Wentz received the B.S. and M.S. degree in physics from Massachusetts Institute of Technology, Cambridge, MA, in 1969 and 1971, respectively.

$\mathrm{He}$ is the founder of Remote Sensing Systems (RSS), Santa Rosa, CA, a research company specializing in satellite microwave remote sensing of the earth. His research focuses on radiative transfer models that relate satellite observations to geophysical parameters, with the objective of providing reliable geophysical datasets to the Earth Science community. As a member of the National Aeronautics and Space Administration's (NASAS) SeaSat Experiment Team (1978-1982), he pioneered the development of physically based retrieval methods for microwave scatterometers and radiometers. Starting in 1987 , he took the lead on providing the world-wide research community with high-quality ocean products derived from satellite microwave imagers (SSM/I). As the Director of RSS, he overseas the production and validation of reliable scatterometer and radiometer products. These data are dispersed via the company's web and ftp sites. He is currently a member of NASA Earth Observation System Investigators Working Group, NASA Advanced Microwave Scanning Radiometer Team, NASA Ocean Vector Wind Science Team, NASA Tropical Rainfall Mission Team, and NASA Pathfinder Activity. He is currently working on scatterometer/radiometer combinations, satellite-derived decadal time series of atmospheric moisture and temperature, the measurement of sea-surface temperature through clouds, and advanced microwave sensor designs for climatological studies

Mr. Wentz has served on many NASA review panels, the National Research Council's Earth Studies Board, the National Research Council's Panel on Reconciling Temperature Observations, and is a member of the American Geophysical Union. 